\title{
Analysis of Fission Products on the AGR-1 Capsule Components
}

Paul A. Demkowicz

Jason M. Harp

Philip L. Winston

Scott A. Ploger

March 2013
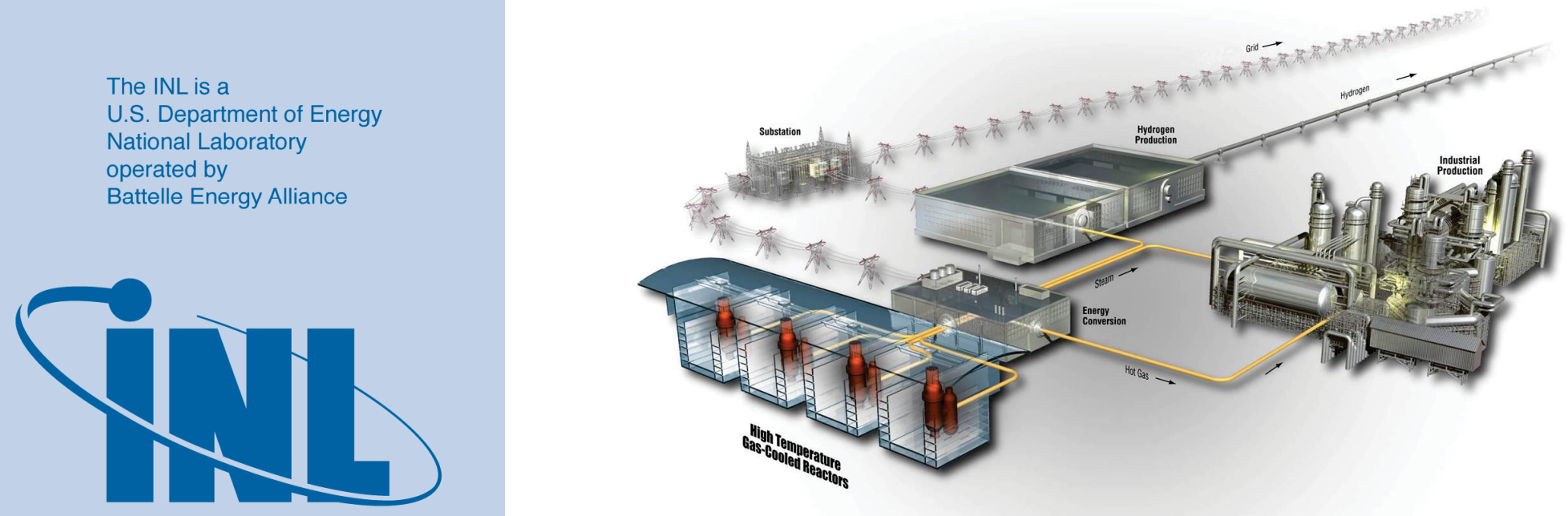

Idaho National Laboratory 


\section{DISCLAIMER}

This information was prepared as an account of work sponsored by an agency of the U.S. Government. Neither the U.S. Government nor any agency thereof, nor any of their employees, makes any warranty, expressed or implied, or assumes any legal liability or responsibility for the accuracy, completeness, or usefulness, of any information, apparatus, product, or process disclosed, or represents that its use would not infringe privately owned rights. References herein to any specific commercial product, process, or service by trade name, trade mark, manufacturer, or otherwise, does not necessarily constitute or imply its endorsement, recommendation, or favoring by the U.S. Government or any agency thereof. The views and opinions of authors expressed herein do not necessarily state or reflect those of the U.S. Government or any agency thereof. 
INL/EXT-13-28483

\title{
Analysis of Fission Products on the AGR-1 Capsule Components
}

\author{
Paul A. Demkowicz \\ Jason M. Harp \\ Philip L. Winston \\ Scott A. Ploger
}

March 2013

\section{Idaho National Laboratory \\ Very High Temperature Reactor Technology Development Office Idaho Falls, Idaho 83415}

http://www.inl.gov

Prepared for the

U.S. Department of Energy

Office of Nuclear Energy

Under DOE Idaho Operations Office

Contract DE-AC07-05ID14517 



\section{Very High Temperature Reactor Technology Development Office}

\section{Analysis of Fission Products on the AGR-1 Capsule Components}

INL/EXT-13-28483

March 2013

Approved by:

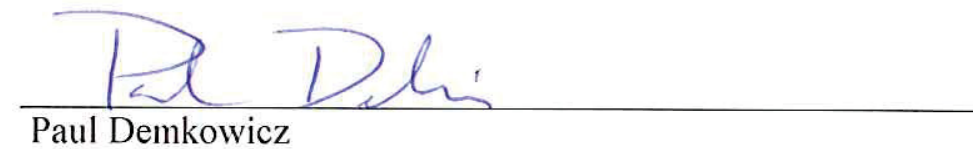

VHTR Fuels Post-Irradiation Examination Technical Lead
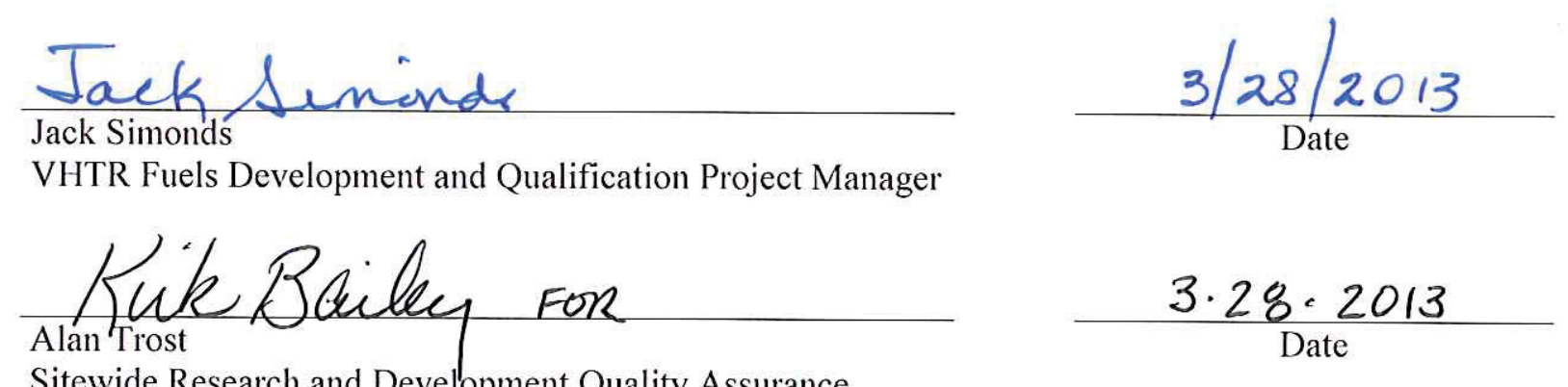

Sitewide Research and Development Quality Assurance
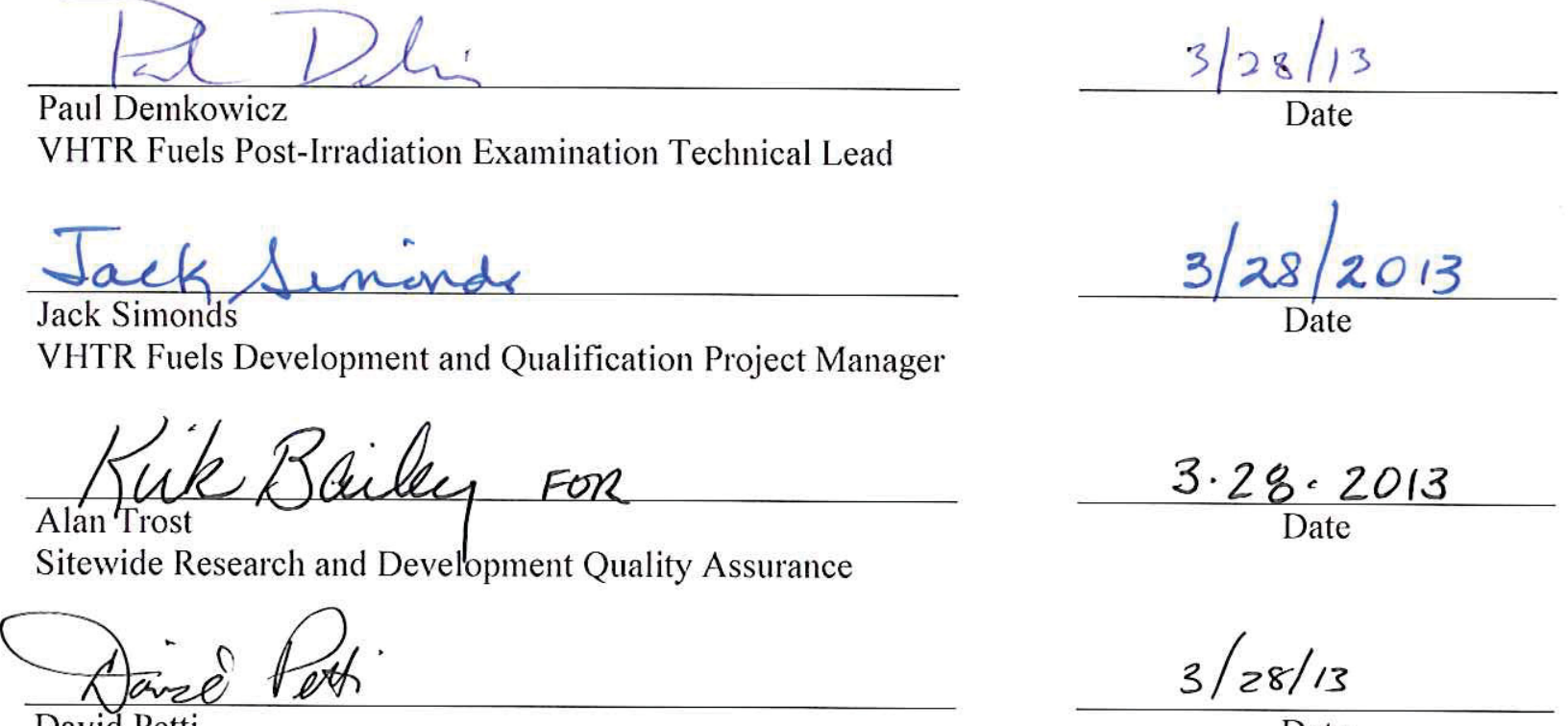

David Petti

VHTR Research and Development Director

$3 \cdot 28 \cdot 2013$

Date

$\frac{3 / 28 / 13}{\text { Date }}$ 



\section{SUMMARY}

The components of the Advanced Gas Reactor (AGR)-1 irradiation capsules were analyzed to measure the retained inventory of fission products in order to determine the extent of in-pile fission product release from the fuel compacts. This includes analysis of (1) the metal capsule components, (2) the graphite fuel holders, (3) the graphite spacers, and (4) the gas exit lines. The fission products most prevalent in the components were Ag-110m, Cs-134, Cs-137, Eu-154, and Sr-90, and the most common locations were the metal capsule components and the graphite fuel holders. Gamma scanning of the graphite fuel holders also was performed to determine spatial distribution of $\mathrm{Ag}-110 \mathrm{~m}$ and radiocesium.

Silver was released from the fuel components in significant fractions. The total Ag- $110 \mathrm{~m}$ inventory found in the capsules ranged from $1.2 \times 10^{-2}$ (Capsule 3 ) to $3.8 \times 10^{-1}$ (Capsule 6). Ag- $110 \mathrm{~m}$ was not distributed evenly in the graphite fuel holders; it tended to concentrate at the axial ends of the graphite holders in Capsules 1 and 6 (located at the bottom and top of the test train) and near the axial center in Capsules 2, 3, and 5 (in the center of the test train). Ag-110m further tended to be concentrated around fuel Stacks 1 and 3, which are the two stacks facing the Advanced Test Reactor core and have higher burnup, neutron fluence, and temperatures when compared with Stack 2. Detailed correlation of silver release with fuel type and irradiation temperatures is problematic at the capsule level due to the large range of temperatures experienced by individual fuel compacts in each capsule. A comprehensive Ag-110m mass balance for the capsules was performed using measured inventories of individual compacts and the inventory on the capsule components. For most capsules, the mass balance was within $11 \%$ of the predicted inventory. The Ag- $110 \mathrm{~m}$ release from individual compacts often exhibited a very large range within a particular capsule.

Cesium release from particles with intact silicon carbide ( $\mathrm{SiC}$ ) was extremely low, with the Cs-134 inventory in the capsule components averaging less than $3 \times 10^{-6}$ in Capsules 1 through 4 . In Capsules 5 and 6, gamma scanning data indicated that specific compacts may have contained one or more particles with defective or failed $\mathrm{SiC}$. The total fractional inventory of $\mathrm{Cs}-134$ found in the Capsule 6 components was $1.33 \times 10^{-5}$. Gamma scanning of the graphite holder from this capsule revealed a region with a slightly elevated Cs-134 concentration near the original location of Compact 6-3-2. Subsequent deconsolidation-leachburn-leach analysis of this compact revealed a single particle with defective or failed $\mathrm{SiC}$ that presumably is responsible for the cesium release. The total fractional inventory of Cs-134 found in the Capsule 5 components was $1.22 \times 10^{-5}$, and gamma scans indicated elevated Cs-134 levels near the original location of Compacts 5-2-1 and 5-2-3. Subsequently, Compact 5-2-3 was deconsolidated, the particles gamma counted, and two particles that lost approximately $30 \%$ of their predicted inventory were located. Non-destructive examination of these particles indicated that both had intact outer pyrocarbon; however, they exhibited fractures in the $\mathrm{SiC}, \mathrm{IPyC}$, and buffer layers, which is consistent with in-pile cesium release but no fission gas release. The experience with Capsules 5 and 6 demonstrates that gamma scanning is capable of detecting Cs-134 activity totaling less than a single particle equivalent inventory and identifying compacts suspected of containing particles with $\mathrm{SiC}$ defects for further analysis. 
Europium release from the compacts was at a level exceeding a single particle inventory in all capsules. Fractional Eu-154 inventory in the capsules ranged from 1.30 to $4.75 \times 10^{-4}$, indicating that a small quantity of europium is being released through intact $\mathrm{SiC}$ in this fuel. Fractional inventory of $\mathrm{Sr}-90$ was less than $10^{-5}$ in all but Capsule 1 (where the value was $2.8 \times 10^{-5}$ ), indicating good strontium retention. Ce-144 activity in the capsule components generally was very low (often below detection limits) and was always at a level well below a single particle equivalent inventory. Pd-105 fractional inventory in two of the capsules was in the range of $10^{-3}$ to $10^{-2}$, indicating significant release from intact coatings.

The results demonstrate that the AGR-1 fuel exhibits excellent retention of cesium during irradiation, and that capsule-average silver release was as high as $38 \%$. Strontium retention appears to be fairly good, while a small fraction of europium is released from the fuel through the intact $\mathrm{SiC}$ layer. A practical approach for identifying compacts that contain particles with defective $\mathrm{SiC}$, based on measurement of cesium in the graphite fuel holder, has been demonstrated. 


\section{ACKNOWLEDGEMENTS}

The authors gratefully acknowledge the contributions of Douglas Pace regarding development of the fission product concentration mapping technique employed on the AGR-1 graphite holders, along with his preparation of the concentration maps themselves. 


\section{CONTENTS}

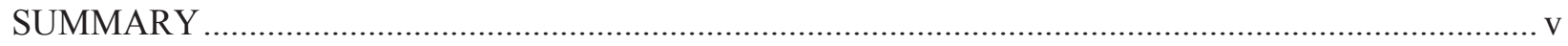

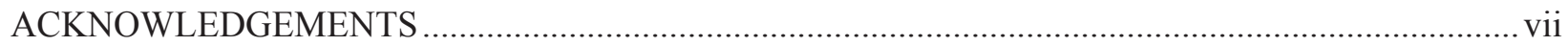

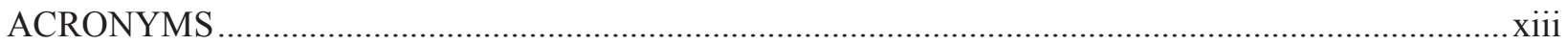

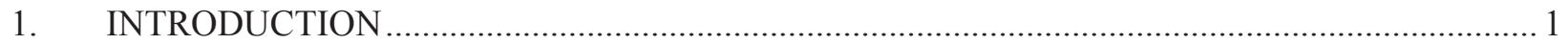

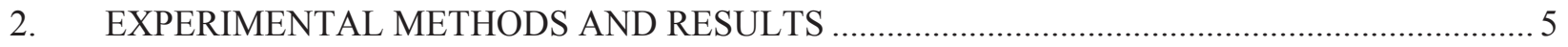

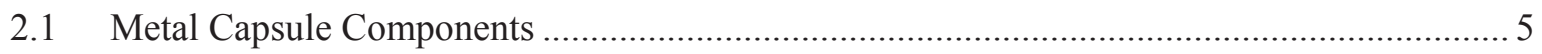

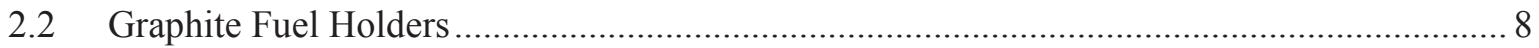

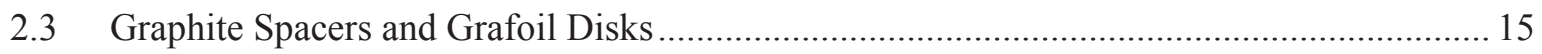

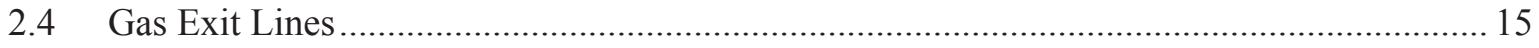

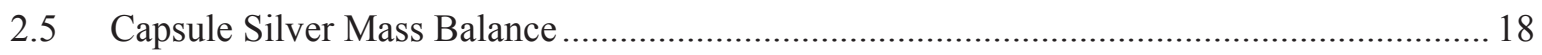

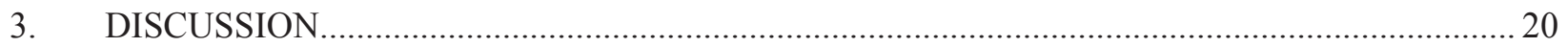

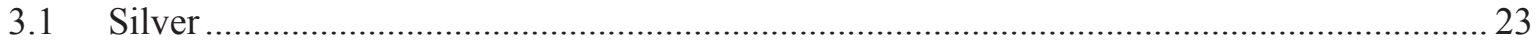

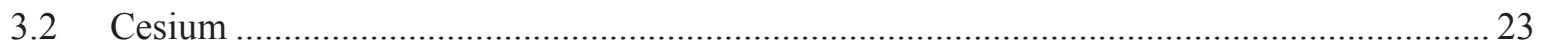

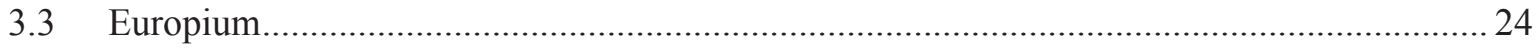

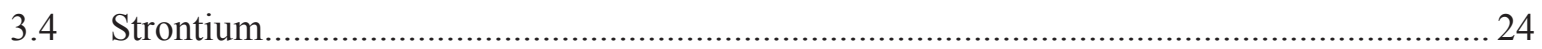

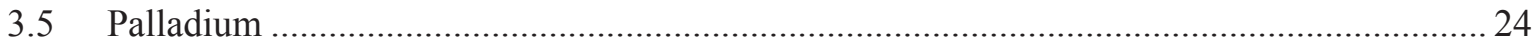

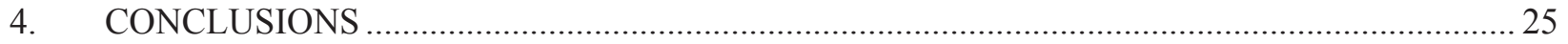

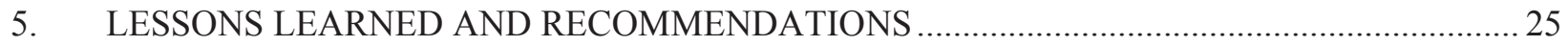

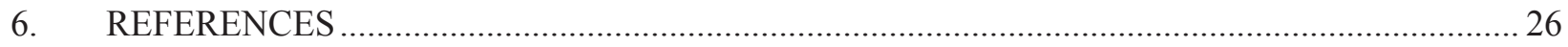

Appendix A Oxidation and Leach of Graphite Fuel Holders .......................................................... 28

\section{FIGURES}

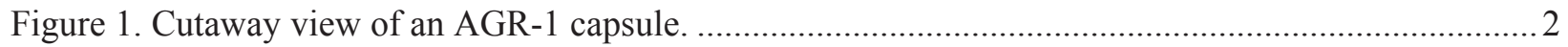

Figure 2. Photograph of an AGR-1 graphite fuel holder shown prior to capsule assembly. The asfabricated diameters of the graphite holders ranged from 3.05 to $3.14 \mathrm{~cm}$. ............................. 3

Figure 3. Cross-section of an AGR-1 irradiation capsule................................................................... 3

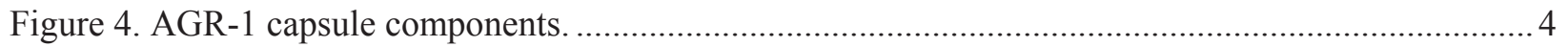

Figure 5. Numbering scheme for AGR-1 compacts. ............................................................................ 4

Figure 6. An AGR-1 capsule head with attached through-tubes and thermocouples (left) and empty capsule shell (right) during capsule disassembly in the INL Hot Fuel Examination Facility... 
Figure 7. Photograph of the inner surface of the top (left) and middle (right) of the AGR-1 Capsule 6 steel shell, indicating the presence of a solid residue (Demkowicz et al. 2011).

Figure 8. Diagram showing the alignment of a $2.22-\mathrm{cm}$ by $0.254-\mathrm{cm}$ collimator for adjacent axial slices on AGR-1 graphite holders (left diagram) as well as the alignment of the collimator (rotated 90 degrees) for the subsequent transverse slices at specific axial locations used to produce cross-sectional maps of the holders (right diagram). All dimensions are provided in centimeters.

Figure 9. Axial distribution of Ag-110m in the AGR-1 graphite holders.

Figure 10. Relative Ag-110m concentration found in Holder 3, Level 2 (left) and Holder 5, Level 3 (right). The identification of specific compacts originally in these locations in the holders is provided.

Figure 11. Axial distribution of Cs-134 and Cs-137 in the AGR-1 Capsule 5 graphite holder. 12

Figure 12. Cs-134 activity intensity map at Level 2 of the Capsule 5 graphite holder. 13

Figure 13. Retained Ag-110m fraction for AGR-1 compacts.

Figure 14. Fraction of predicted total capsule Ag-110m inventory found in the compacts, on the metal capsule components ("shells"), the graphite spacers, and the graphite holder for each capsule. The total percent of the predicted inventory accounted for is listed at the top of each column.

Figure 15. Fractional inventory of Cs-134 in the AGR-1 capsules components.

Figure 16. Fractional inventory of Eu-154 in the AGR-1 capsule components......................................21

Figure 17. Fractional inventory of Ag-110m in the AGR-1 capsule components..................................22

Figure 18. Fractional inventory of Sr-90 in the AGR-1 capsule components......................................... 22

Figure A1. Flow diagram of the fusion-leach-oxidation-leach process for the AGR-1 graphite fuel holders.

\section{TABLES}

Table 1. Fuel type irradiated in each AGR-1 capsule. .5

Table 2. Decay-corrected activity and capsule inventory fraction of fission products on the AGR1 metal capsule components. 8

Table 3. Decay-corrected measured activity and capsule inventory fraction for AGR-1 graphite fuel holders.

Table 4. Decay-corrected activity and capsule inventory fraction of gamma-emitting fission products in the graphite spacers and Grafoil disks from the AGR-1 capsules.

Table 5. Capsule fraction of Ag-110m measured in gas exit line segments. Segments represented by blue cells have been gamma counted. Segments represented by green cells were prepared but were not counted.

Table 6. Average minimum detectable activity for selected isotopes taken from the reported limits of all gas line segments for which the isotope was not detected. 
Table 7. Total fractional inventory of selected fission products found in the AGR-1 capsule components.

Table A1. Ratio of decay-corrected gamma activity measured in the graphite holder leach solutions to the decay-corrected gamma activity measured in the solid graphite holder pieces.

Table A2. Decay-corrected activity and capsule fraction of Sr-90 measured in the graphite holder leach solutions.

Table A3. Measured mass of Pd-105 in the AGR-1 graphite holders and corresponding capsule fraction. 


\section{ACRONYMS}

AGR Advanced Gas Reactor

ATR Advanced Test Reactor

HPGe high-purity germanium

ICP-AES inductively coupled plasma atomic emission spectroscopy

ICP-MS inductively coupled plasma mass spectrometry

IMGA irradiated microsphere gamma analyzer

INL Idaho National Laboratory

MFC Materials and Fuels Complex

NGNP Next Generation Nuclear Plant

PIE post-irradiation examination

TRISO tristructural isotropic

VHTR Very high temperature reactor 


\section{Analysis of Fission Products on the AGR-1 Capsule Components}

\section{INTRODUCTION}

As part of the Next Generation Nuclear Plant (NGNP) project Fuel Development and Qualification Program, a series of irradiation experiments are being performed to evaluate the performance of tristructural isotropic (TRISO) coated particle fuel (Simonds 2010). The first of these experiments was Advanced Gas Reactor (AGR)-1, which was irradiated in the Advanced Test Reactor (ATR) from December 2006 to November 2009. The AGR-1 fuel particles consist of 350- $\mu \mathrm{m}$ diameter uranium oxide/uranium carbide kernels fabricated at Babcock and Wilcox Nuclear Operations Group and coated at Oak Ridge National Laboratory with porous carbon buffer $(100 \mu \mathrm{m})$, inner pyrolytic carbon $(40 \mu \mathrm{m})$, silicon carbide $(35 \mu \mathrm{m})$, and outer pyrolytic carbon $(40 \mu \mathrm{m})$ layers. Uranium enrichment in the kernels is 19.7\% (Maki 2009). The particles were pressed into right cylindrical compacts nominally $25 \mathrm{~mm}$ (approximately 1 inch) in length and $12.4 \mathrm{~mm}$ (approximately $1 / 2$ inch) in diameter, each containing approximately 4,100 coated particles.

A baseline fuel type and three fuel variants were included in the AGR-1 irradiation, with each variant fabricated by varying one step of the coating process to produce slightly different inner pyrolytic carbon or silicon carbide ( $\mathrm{SiC}$ ) coating properties (Maki 2009). One primary goal of the experiment is to identify any fuel performance differences between the fuel types, either during irradiation or during postirradiation, high-temperature safety tests in order to support optimization of the fuel fabrication process and eventual selection of a reference fuel for qualification.

Each AGR-1 irradiation capsule was approximately 6 in. in length and contained 12 fuel compacts in three separate stacks. Figure 1 shows a cutaway diagram of a single AGR-1 capsule. The compacts were retained inside a graphite fuel holder (Figure 2), and a graphite spacer and Grafoil disks were positioned at the top and bottom of the graphite holder to retain the compacts with the holder and to provide thermal insulation. The capsule shell was made of stainless steel and had inner steel and hafnium liners. Six capsules were welded together end-to-end to create the irradiation test train. Three molybdenum through tubes ran the length of each capsule to allow gas inlet and outlet lines and thermocouple leads to be passed from the lower capsules to the top of the test train. Niobium tubes were used to transmit the neonhelium control gas mixture to and from each capsule. A cross-section of an AGR-1 capsule is shown in Figure 3. The individual components of one of the AGR-1 test trains are shown in Figure 4 (photograph taken prior to capsule assembly). Each AGR-1 compact has been given a unique identifier based on the location in the test train. The compacts are numbered by the capsule, the vertical level, and the stack, as shown in Figure 5. Note that the levels are numbered starting at the bottom of each capsule. The test train is discussed in further detail in Maki 2009.

Each AGR-1 capsule contained one fuel type. Table 1 lists the fuel types for each capsule. The experiment was irradiated for 620 effective full-power days in the ATR and achieved a calculated compact average peak burnup of $19.5 \%$ fissions per initial heavy metal atom, with zero particle failures observed based on the measured fission gas release-to-birth ratios (Collin 2012). The time-average volume average temperature for the fuel compacts ranged from 955 to $1136^{\circ} \mathrm{C}$ and the time-average maximum temperature ranged from 1069 to $1197^{\circ} \mathrm{C}$ (Hawkes 2012).

The post-irradiation examination (PIE) of coated particle fuel focuses primarily on verifying coating integrity and fission product retention of the fuel during normal irradiation conditions and during offnormal accident scenarios. Because AGR-1 is the first irradiation of its kind in the NGNP project and involves a complex, multi-capsule, instrumented lead experiment containing four different types of fuel, 
PIE also will seek to investigate the performance of the test train and components. The specific objectives and planned PIE activities for the AGR-1 experiment are presented in the AGR-1 PIE plan (Demkowicz 2010).

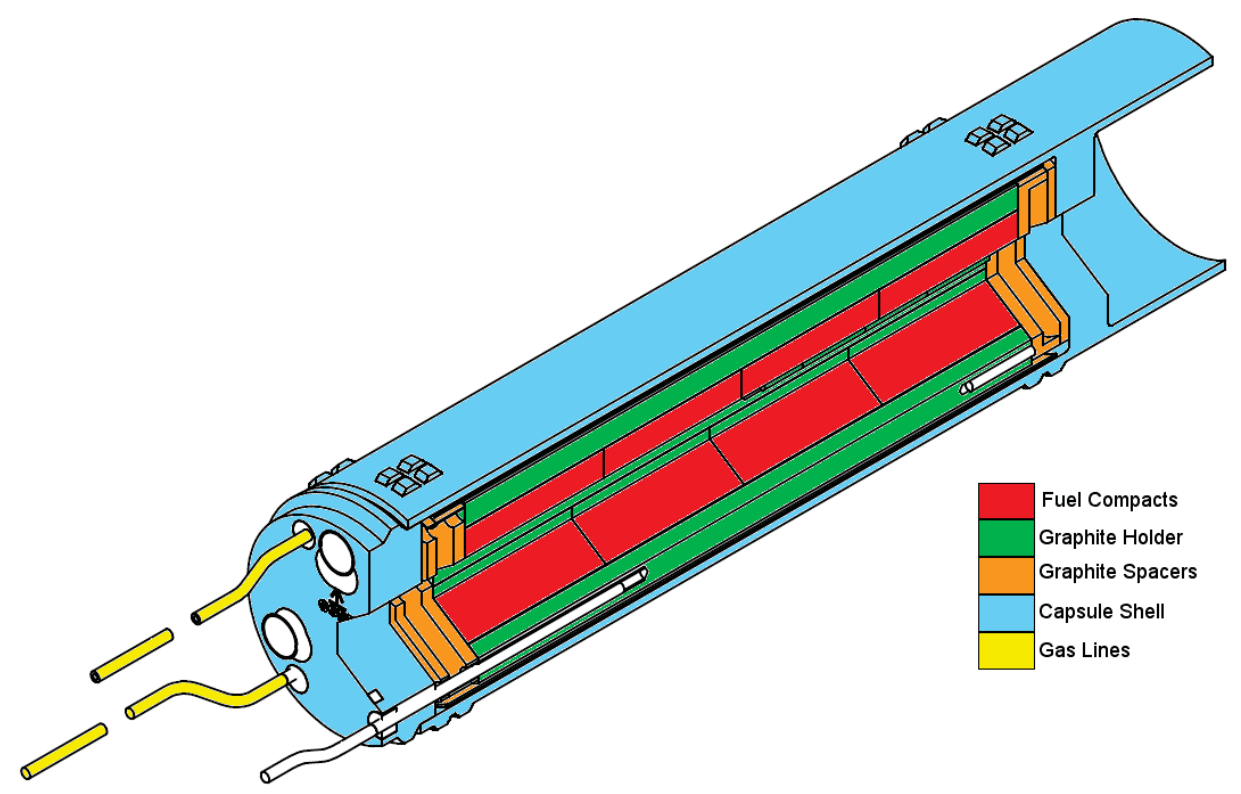

Figure 1. Cutaway view of an AGR-1 capsule. 


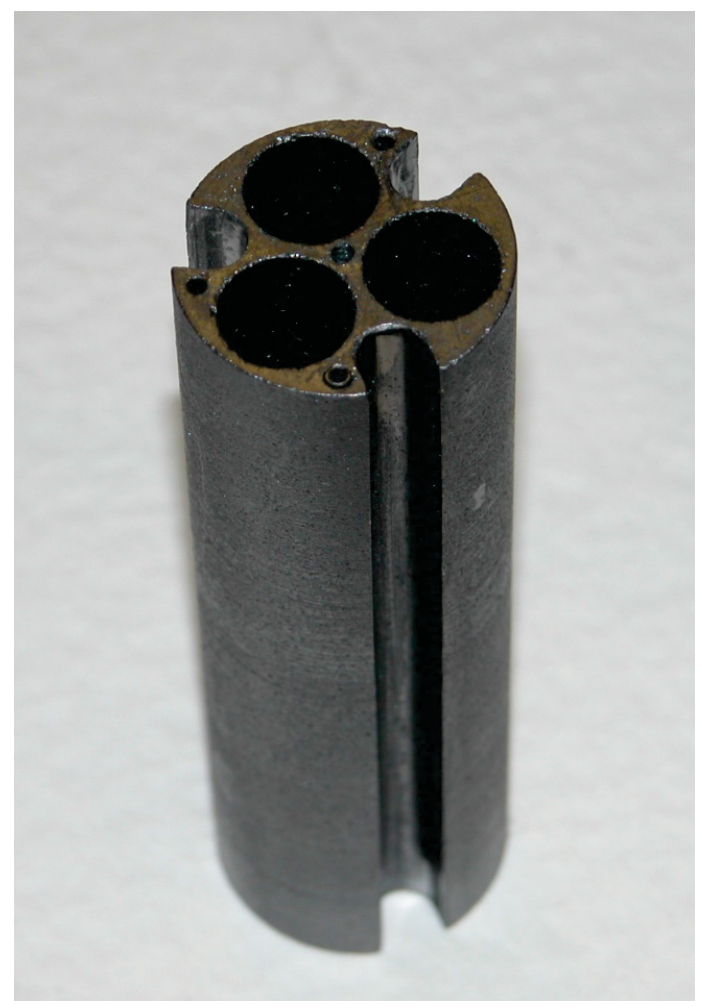

Figure 2. Photograph of an AGR-1 graphite fuel holder shown prior to capsule assembly. The as-fabricated diameters of the graphite holders ranged from 3.05 to $3.14 \mathrm{~cm}$.

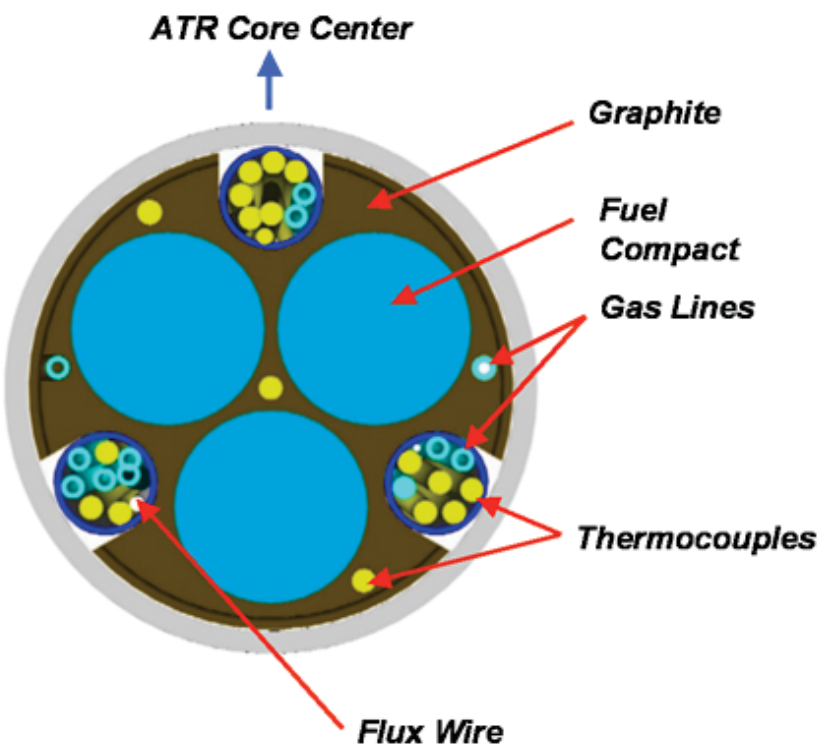

Figure 3. Cross-section of an AGR-1 irradiation capsule. 


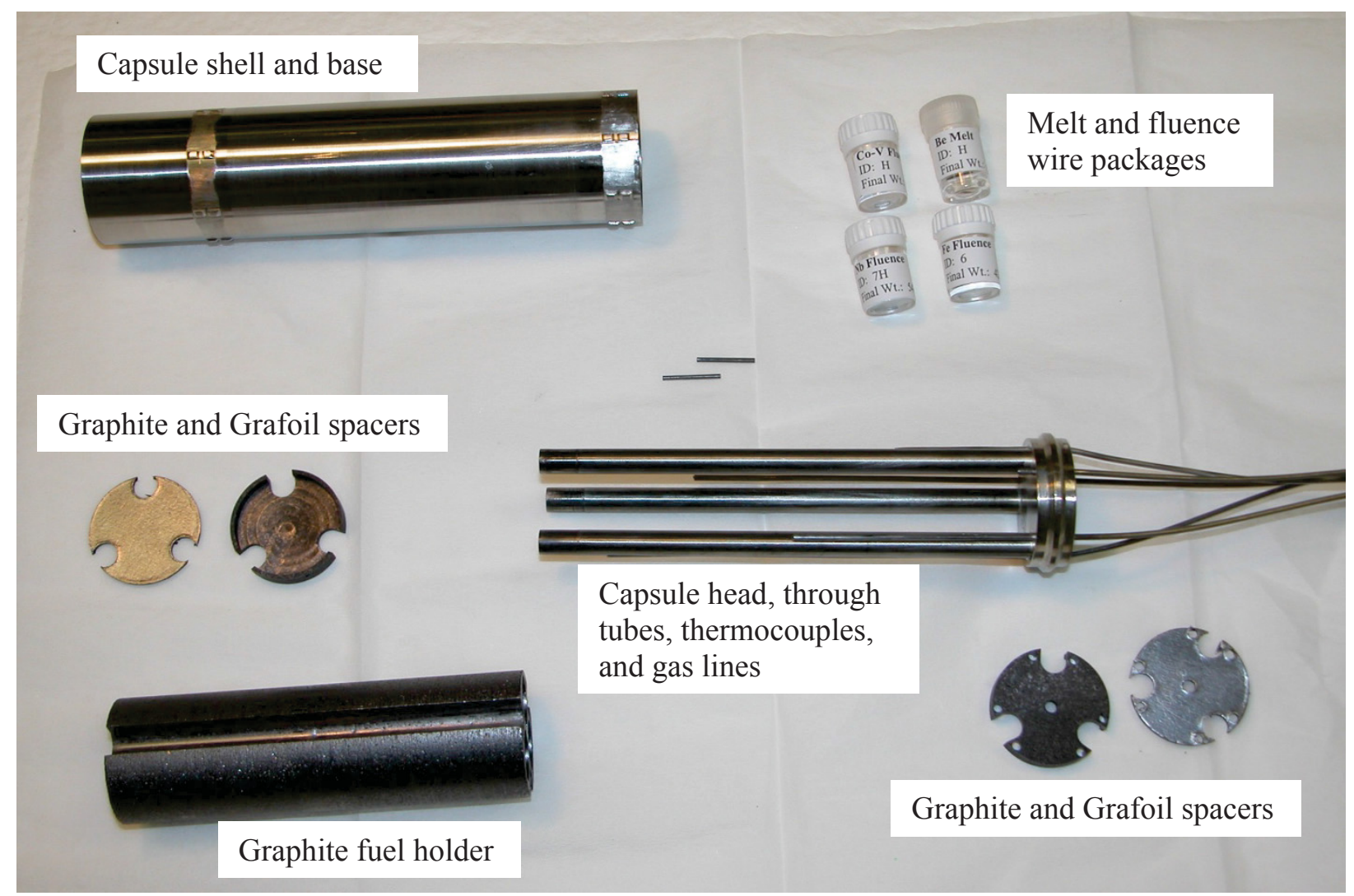

Figure 4. AGR-1 capsule components.

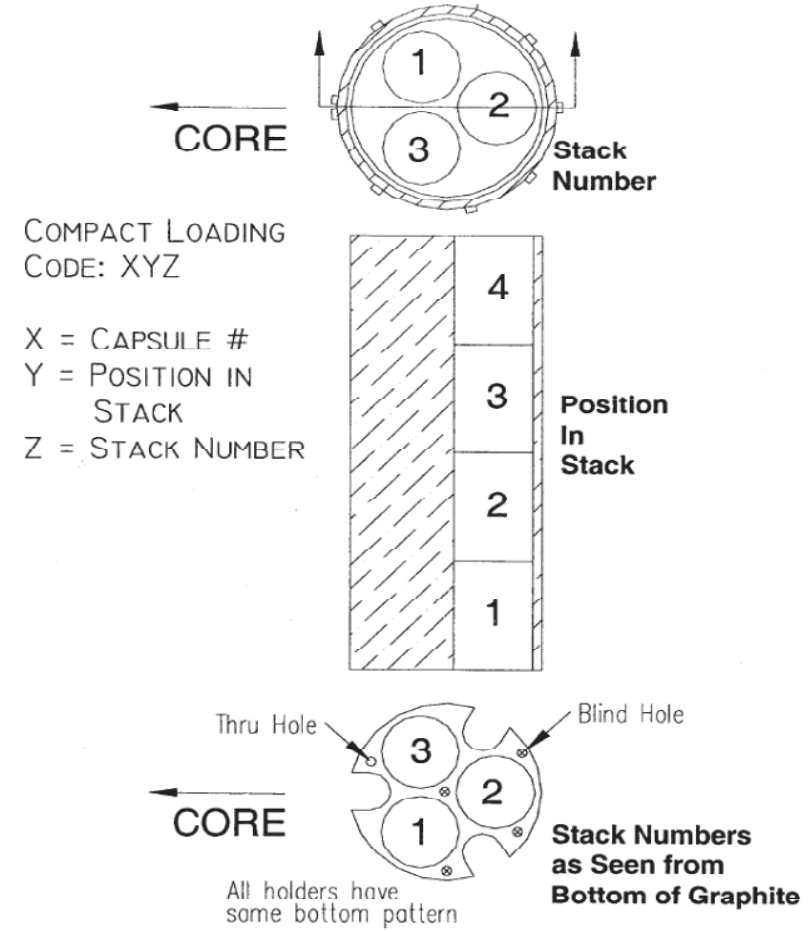

Figure 5. Numbering scheme for AGR-1 compacts. 
Table 1. Fuel type irradiated in each AGR-1 capsule.

\begin{tabular}{cc} 
Capsule & Fuel Type \\
\hline 6 & Baseline \\
5 & Variant 1 \\
4 & Variant 3 \\
3 & Baseline \\
2 & Variant 2 \\
1 & Variant 3 \\
\hline
\end{tabular}

The test train was shipped to the Materials and Fuels Complex (MFC) at the Idaho National Laboratory (INL) for PIE in March 2010. Disassembly of the capsules and dimensional measurements of the fuel compacts and graphite holders has been presented in detail elsewhere (Demkowicz et al. 2011).

In-pile fission product release was evaluated by analyzing the AGR-1 capsule components to measure the inventory of key fission products that had been released from the fuel compacts and deposited on the various components. This included analysis of (1) the metal capsule components, including the steel capsule shell, steel capsule head and base, and molybdenum through tubes; (2) the graphite fuel holders; (3) the graphite spacer and Grafoil disks; and (4) the sweep gas exit lines. This report presents the experimental methods used and the results of the fission product inventory measurements on these capsule components.

\section{EXPERIMENTAL METHODS AND RESULTS}

\subsection{Metal Capsule Components}

The metal capsule components from all capsules were cut into smaller pieces in order to fit into plastic containers (approximately $85 \mathrm{~mm}$ long $\times 40 \mathrm{~mm}$ diameter) and sent to the MFC Analytical Laboratory hot cells. Photographs of several capsule components during disassembly in the MFC Hot Fuel Examination Facility main hot cell are shown in Figure 6. The components were chemically leached to dissolve any fission products on the surfaces. Leaching was necessary to extract the trace quantity fission products from the highly activated steel to facilitate detection.

Capsule 6 was analyzed first and the experiment involved some process development to refine the leaching conditions necessary to effectively remove all deposited fission products. During disassembly, a noticeable amount of unidentified residue was observed on the inner diameter of several of the capsule shells after removal of the graphite fuel holder (Demkowicz et al. 2011). This residue was most conspicuous in the outer two capsules (Capsules 1 and 6); a photograph of the Capsule 6 shell showing the residue is presented in Figure 7. Samples of this residue were scraped from the Capsule 6 shell so they could be dissolved and analyzed separately. A total mass of $0.112 \mathrm{~g}$ of residue was removed from the shell, dissolved in $8 \mathrm{M}$ nitric acid, and analyzed for fission product activity. It was found that a significant fraction of the total capsule inventory of certain fission products (including about $70 \%$ of the measured Ag- $110 \mathrm{~m}$ activity) was in the residue. The stainless steel capsule shell (including the hafnium and steel foil liners) and upper and lower end caps (with short sections of the molybdenum through tubes still attached) were submersed in $8 \mathrm{M} \mathrm{HNO}_{3}$ at a near-boiling temperature for 30 minutes. A white precipitate formed in the solutions from the end caps, which was determined to be $\mathrm{MoO}_{3}$ formed from dissolved molybdenum from the through tube pieces. Efforts to redissolve this precipitate were unsuccessful, so the solid was collected, dried, and gamma counted and the measured activity added to the totals for Capsule 6 (the actual contribution from this solid to the totals was very small for all fission products measured). Because of the issue of molybdenum dissolution and reprecipitation as $\mathrm{MoO}_{3}$, the main sections of the 
molybdenum through tubes were immersed in $8 \mathrm{M} \mathrm{HNO}_{3}$ for 60 seconds at ambient temperature to remove fission products while avoiding complete dissolution of the components. All of the leach solutions from the metal components were combined for a single measurement of total activity. In order to verify that all fission products had been removed from the metal components, an additional leach step was performed on the steel shell and the top and bottom end caps by immersing them in $12 \mathrm{M} \mathrm{HCl}$ for 10 minutes. This was determined to be a sufficiently aggressive etch to remove about $1 \mu \mathrm{m}$ of the steel surface. Subsequent gamma analysis of this solution found significant activity of Co-60 (from the activated steel), but no detectable fission product activity. The conclusion was that the initial $\mathrm{HNO}_{3}$ etch was adequate to remove deposited fission products from the steel surfaces, and the additional $\mathrm{HCl}$ etch was not performed on the remaining capsules.

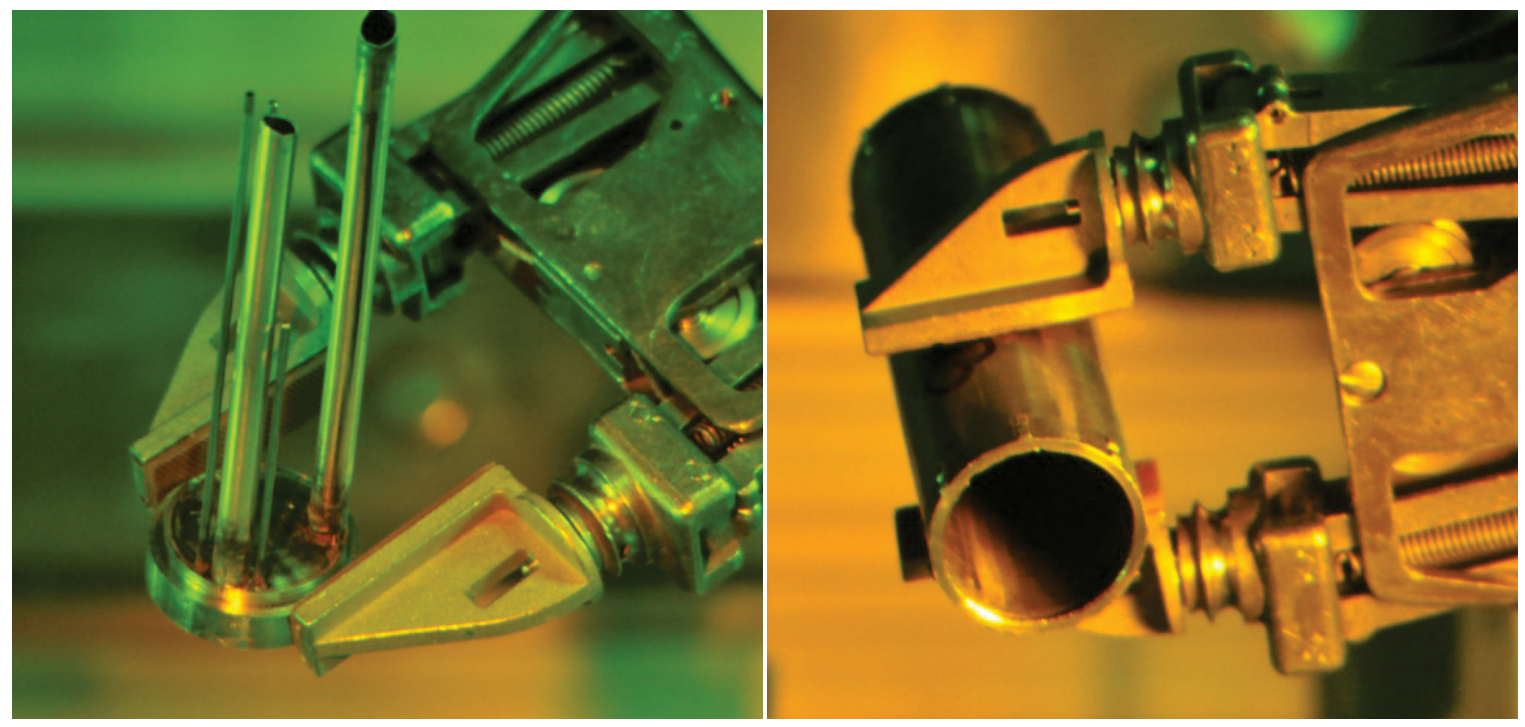

Figure 6. An AGR-1 capsule head with attached through-tubes and thermocouples (left) and empty capsule shell (right) during capsule disassembly in the INL Hot Fuel Examination Facility.
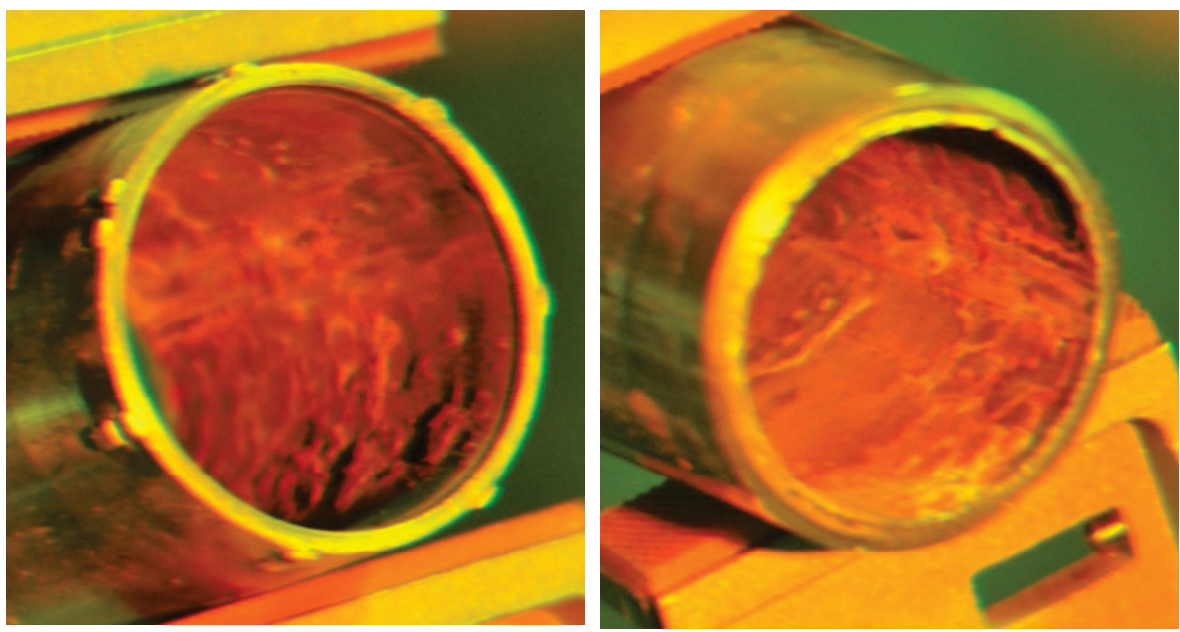

Figure 7. Photograph of the inner surface of the top (left) and middle (right) of the AGR-1 Capsule 6 steel shell, indicating the presence of a solid residue (Demkowicz et al. 2011).

The metal components from the remaining five capsules were analyzed in a uniform manner, based on lessons learned from processing of the Capsule 6 components. The molybdenum through tubes and 
steel shells were processed as described for Capsule 6, with the exception that the residue on the shell's inner diameter was not scraped off for separate analysis but was dissolved when the shells were immersed in hot $\mathrm{HNO}_{3}$. The process for the end caps was modified based on the Capsule 6 experience in order to avoid the precipitation of $\mathrm{MoO}_{3}$. The components were first immersed in $8 \mathrm{M} \mathrm{HNO}_{3}$ for 60 minutes to dissolve all remnants of the molybdenum through tubes without precipitating $\mathrm{MoO}_{3}$. This solution was decanted off to remove the dissolved molybdenum and then the remaining steel end caps were immersed in $8 \mathrm{M} \mathrm{HNO}_{3}$ at near-boiling temperature to complete the dissolution of fission products on the steel surfaces. All of the solutions for a specific capsule were combined and a single measurement made of the consolidated solution.

Gamma spectrometry was performed on the leach solutions from each capsule to determine the activity for gamma-emitting isotopes. The gamma spectrometry system for these samples utilized the in-cell spectrometer located in the Analytical Laboratory A-wing. This detector is an $18 \%$ relative efficiency $+2500 \mathrm{~V} \mathrm{Ge}(\mathrm{Li})$ coaxial detector, Canberra Model GC1820. It is connected to a digital multichannel analyzer and utilizes the APEX software package from Canberra. The detector is housed in a shielded port that has a lead-lined collimator tube that protrudes into the hot cell. Solutions were evaluated in 30-mL Nalgene poly bottles that are placed at specific calibrated distances from the collimator. The calibration source consists of $30 \mathrm{~mL}$ of liquid containing a known amount of multi-line standard in a 30-mL Nalgene poly bottle, providing calibration from 59.4 to $1,806 \mathrm{keV}$. Strontium separation was performed on aliquots of the leachate from each sample and then analyzed via a gas flow proportional counter to ascertain the Sr-90 activity. During separation, an aliquot of the dissolution was traced with a stable strontium carrier and then extracted from the liquid matrix using Eichrom's Sr-SPEC resin. The eluent from the extraction column was precipitated as a carbonate, filtered on a tared filter, dried, and weighed. The filter was counted and the activity was corrected for the yield, which was attained gravimetrically, based on the percent recovery of the stable tracer. ICP-MS was also performed on the solutions to quantify the inventory of other non-gamma-emitting isotopes.

Activities for selected fission product radioisotopes found on the metal capsule components, as well as the corresponding fraction of predicted capsule activity, are shown in Table 2. All measured activities presented in this report were decay-corrected to November 7, 2009, 12:00 GMT (the end of the AGR-1 irradiation plus one day) to correspond to the date and time of the predicted inventories from AGR-1 physics simulations (Sterbentz 2011). Decay corrections were performed using the following equation:

$A=A_{o} e^{-\lambda t}$

where $\mathrm{A}$ is the activity at time $t, A_{o}$ is the activity at $t=0$, and $\lambda$ is the decay constant $\left(\lambda=\ln (2) / t_{1 / 2}\right.$, and $t_{1 / 2}$ is the half life). Isotope half life data were taken from the ENDF/B-VII.1 library (Chadwick et al. 2011). Note that for some solutions, no activity was detected for certain isotopes and the minimum detectable activity was used to calculate the decay-corrected activity and the corresponding capsule fractions reported in Table 2 (reported as " $<$ " the specified value). Therefore, these should be considered as an effective upper bound on the activity actually present on the components. All of the capsule fractions in this report were calculated by dividing the decay-corrected measured activity by the predicted capsule inventory (Sterbentz 2011). Note that with approximately 50,000 particles in each capsule, a capsule fraction of $2.0 \times 10^{-5}$ corresponds to the average inventory of one particle.

The Ag-110m fraction in all capsules was significant, ranging from $5.1 \times 10^{-3}$ to $3.5 \times 10^{-1}$. No Cs-134 or Cs-137 was detected in the metal components in Capsules 1 through 4, while both Capsule 5 and Capsule 6 had measureable activity of Cs-134 and Cs-137, with good agreement between the fractions determined from the two isotopes. As will be discussed in the next section, an elevated inventory of cesium was detected in the graphite holders from Capsules 5 and 6, which correlates with the higher activities on the metal capsule components indicated in Table 2. No Ce-144 was detected on the metal components in any of the capsules. Eu-154 was only detected on the metal capsule components from 
Capsules 2 and 3. Sr-90 was measured on the metal components of all six capsules, although fractional inventories were very low, ranging from $2.7 \times 10^{-7}$ to $9.7 \times 10^{-6}$.

Various fission product isotopes were measured with mass spectrometry. In most cases these had very low fractional inventories. One of the isotopes of primary interest is Pd-105, which was found to be present on the capsules at fractions of less than $6 \times 10^{-5}$. The fraction of Te-128 found on the capsules was approximately $10^{-2}$, but the measured values appeared to be very close to the detection limit of the method and therefore it is likely that these values are unreliable.

Table 2. Decay-corrected activity and capsule inventory fraction of fission products on the AGR-1 metal capsule components.

Decay-Corrected Activity (Bq)

\begin{tabular}{ccccccc}
\hline Capsule & Ag-110m & Cs-134 & Cs-137 & Ce-144 & Eu-154 & Sr-90 \\
6 & $3.97 \mathrm{E}+08$ & $1.40 \mathrm{E}+06$ & $1.54 \mathrm{E}+06$ & $<9.4 \mathrm{E}+06$ & $<5.1 \mathrm{E}+05$ & $2.11 \mathrm{E}+05$ \\
5 & $2.99 \mathrm{E}+07$ & $5.17 \mathrm{E}+05$ & $5.47 \mathrm{E}+05$ & $<4.6 \mathrm{E}+05$ & $<2.8 \mathrm{E}+05$ & $2.63 \mathrm{E}+05$ \\
4 & $2.94 \mathrm{E}+07$ & $<5.6 \mathrm{E}+05$ & $<3.7 \mathrm{E}+05$ & $<6.7 \mathrm{E}+06$ & $<6.0 \mathrm{E}+05$ & $1.80 \mathrm{E}+06$ \\
3 & $2.33 \mathrm{E}+07$ & $<6.3 \mathrm{E}+05$ & $<5.4 \mathrm{E}+04$ & $<7.9 \mathrm{E}+06$ & $3.55 \mathrm{E}+06$ & $2.27 \mathrm{E}+05$ \\
2 & $1.43 \mathrm{E}+07$ & $<2.3 \mathrm{E}+05$ & $<1.7 \mathrm{E}+05$ & $<3.0 \mathrm{E}+06$ & $7.82 \mathrm{E}+05$ & $4.95 \mathrm{E}+04$ \\
1 & $4.43 \mathrm{E}+08$ & $<4.4 \mathrm{E}+05$ & $<2.4 \mathrm{E}+05$ & $<4.5 \mathrm{E}+06$ & $<3.7 \mathrm{E}+05$ & $2.89 \mathrm{E}+05$ \\
\hline \multicolumn{7}{c}{ Capsule Fraction } \\
\hline Capsule & Ag-110m & Cs-134 & Cs-137 & Ce-144 & Eu-154 & Sr-90 \\
6 & $3.52 \mathrm{E}-01$ & $1.00 \mathrm{E}-05$ & $9.31 \mathrm{E}-06$ & $<4.2 \mathrm{E}-06$ & $<1.0 \mathrm{E}-04$ & $1.45 \mathrm{E}-06$ \\
5 & $1.34 \mathrm{E}-02$ & $2.24 \mathrm{E}-06$ & $2.70 \mathrm{E}-06$ & $<1.8 \mathrm{E}-07$ & $<3.7 \mathrm{E}-05$ & $1.52 \mathrm{E}-06$ \\
4 & $9.64 \mathrm{E}-03$ & $<1.9 \mathrm{E}-06$ & $<1.7 \mathrm{E}-06$ & $<2.5 \mathrm{E}-06$ & $<6.6 \mathrm{E}-05$ & $9.69 \mathrm{E}-06$ \\
3 & $7.01 \mathrm{E}-03$ & $<2.0 \mathrm{E}-06$ & $<2.4 \mathrm{E}-07$ & $<3.0 \mathrm{E}-06$ & $3.70 \mathrm{E}-04$ & $1.19 \mathrm{E}-06$ \\
2 & $5.14 \mathrm{E}-03$ & $<8.4 \mathrm{E}-07$ & $<7.8 \mathrm{E}-07$ & $<1.1 \mathrm{E}-06$ & $8.97 \mathrm{E}-05$ & $2.70 \mathrm{E}-07$ \\
1 & $2.63 \mathrm{E}-01$ & $<2.3 \mathrm{E}-06$ & $<1.3 \mathrm{E}-06$ & $<1.9 \mathrm{E}-06$ & $<5.6 \mathrm{E}-05$ & $1.75 \mathrm{E}-06$ \\
\hline
\end{tabular}

\subsection{Graphite Fuel Holders}

The graphite fuel holders were analyzed in a multi-phase approach to determine the relative distribution of gamma-emitting fission products and the overall inventory of fission products within the components. Gamma analysis of the holders has been described in detail in ECAR-1709 (Harp and Ploger 2011) and will be summarized here.

After capsule disassembly, the intact graphite holders were placed in aluminum containers and analyzed with gamma spectrometry using the Precision Gamma Scanner in the Hot Fuel Examination Facility. The Precision Gamma Scanner system consists of a high-purity germanium (HPGe) detector with Compton scatter suppression, a remote positioning stage, a collimator through the hot cell wall, and a control system that automatically and progressively scanned a predefined region. The HPGe detector was calibrated using a combination of Eu- 152 sources of a known activity and a geometry correction based on Monte Carlo simulations of the detector system. The activities from the spatial scans are considered semi-quantitative; more rigorously quantitative activities are discussed later in this section.

Five intact holders were examined. The holder for Capsule 4 was damaged during capsule disassembly (Demkowicz et al. 2011), making scanning of the intact component infeasible. Each holder was scanned in two off-axial sweeps that examined half of the holder in each sweep (as shown in the left 
side of Figure 8). The collimator used in the analysis has a rectangular opening 2.22-cm (0.875-in.) long set to a width of $0.254 \mathrm{~cm}$ (0.100 in.). The sweeps consisted of individual scans at $0.254-\mathrm{cm}(0.100$-in.) increments that spanned from the center of the holder to its edge. This allowed for measurement of the axial distribution of fission products in each half of the holders. Transverse scans were performed in two orthogonal directions at selected axial regions that were found to have elevated fission product concentrations to identify cross-sectional distributions (demonstrated in the right side of Figure 8). A rudimentary tomography scheme was applied to the results of the orthogonal scans to map fission product distribution on a holder cross-section.

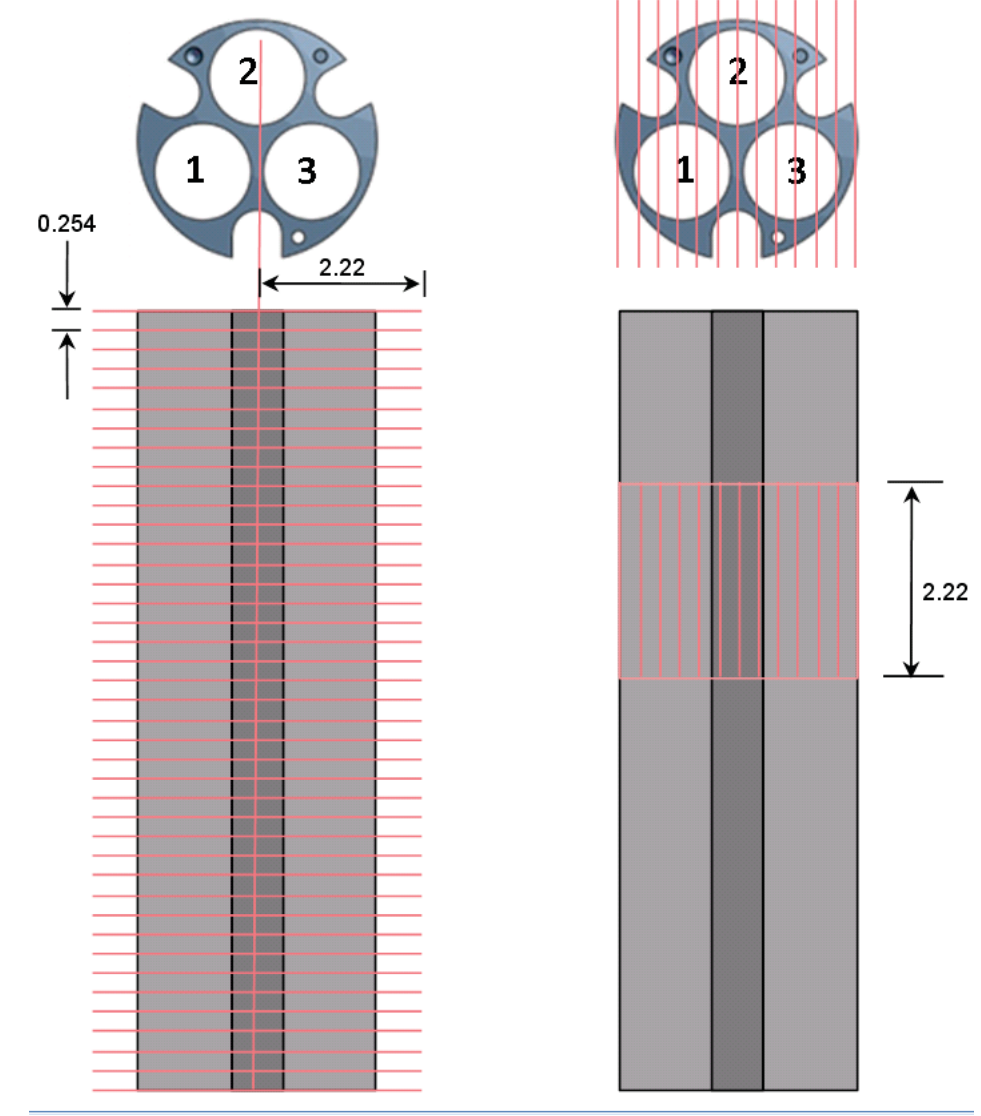

Figure 8. Diagram showing the alignment of a $2.22-\mathrm{cm}$ by $0.254-\mathrm{cm}$ collimator for adjacent axial slices on AGR-1 graphite holders (left diagram) as well as the alignment of the collimator (rotated 90 degrees) for the subsequent transverse slices at specific axial locations used to produce cross-sectional maps of the holders (right diagram). All dimensions are provided in centimeters.

The primary fission product detected in the holders was Ag-110m, although in several cases Cs-134 and Cs-137 were detected. The other consistently detected radionuclide was Co-60, which is an activation product from trace amounts of $\mathrm{Co}, \mathrm{Ni}$, and $\mathrm{Fe}$ in the holder graphite. Trace element analysis of the graphite before irradiation revealed impurity levels of less than $40 \mathrm{ppm}$ for Co and $\mathrm{Ni}$, and less than $350 \mathrm{ppm}$ for Fe. Impurity levels of $\mathrm{Ag}$ and $\mathrm{U}$ in an identical lot of graphite were less than $0.1 \mathrm{ppm}$. As will be discussed, the distribution of Ag-110 $\mathrm{m}$ in the holders and the wide variation in the activity of Ag$110 \mathrm{~m}$ in the holders strongly suggest that the detected Ag-110m is from fission rather than initial Ag impurities in the graphite. 
The axial distribution of $\mathrm{Ag}-110 \mathrm{~m}$ for both halves of the graphite holders is plotted in Figure 9. Note that the top of the holders is oriented at the left of both sets of data. This plot clearly illustrates the high degree of variation in the measured Ag-110m activity in the holders. In most cases, the Ag-110m activity profiles in the left and right halves of the axial scans look very similar. The one exception is Capsule 3 , which has a much more prominent peak at Level 2 (second from the bottom) in the right side of the holder compared to the left side. Higher Ag-110m concentrations are found near the axial ends of holders at the top and bottom of the test train (Holders 6 and 1, respectively), while holders in the center of the test train (Holders 2, 3, and 5) exhibit higher Ag-110m concentrations away from their ends. A satisfactory explanation for this behavior is not available at this time. Because of the axial symmetry of the observation (i.e., similar behavior in Capsules 1 and 6), it is possible that it is related to the nature of the graphite used in the holders and/or the size of the radial gap between the holder and the capsule shell. All of the holders initially contained boron carbide as a burnable poison, with Holders 1 and 6 containing nominally $5.5 \% \mathrm{~B}_{4} \mathrm{C}$ and Holders 2 through 5 containing nominally $7.0 \% \mathrm{~B}_{4} \mathrm{C}$. During post-irradiation measurements of graphite holder dimensions, it was found that Holders 1 and 6 had experienced net diametrical shrinkage, while Holders 2, 3, and 5 had experienced net expansion. The differing behavior is believed to be due in part to the combined effect of the neutron fluence variation across the test train, as well as the effect of energetic ions generated from the ${ }^{10} \mathrm{~B}(n, \alpha)^{7} \mathrm{Li}$ reaction, which occurred with higher frequency in Holders 2 through 5 due to the higher initial boron content. The net effect was an increase in the temperature control gap between the graphite holder and the capsule shell for Capsules 1 and 6 and a decrease in the gap for Capsules 2, 3, and 5 (Demkowicz et al. 2011). Whether these differences in the control gap played a role in the silver distributions shown in Figure 9 is not known.

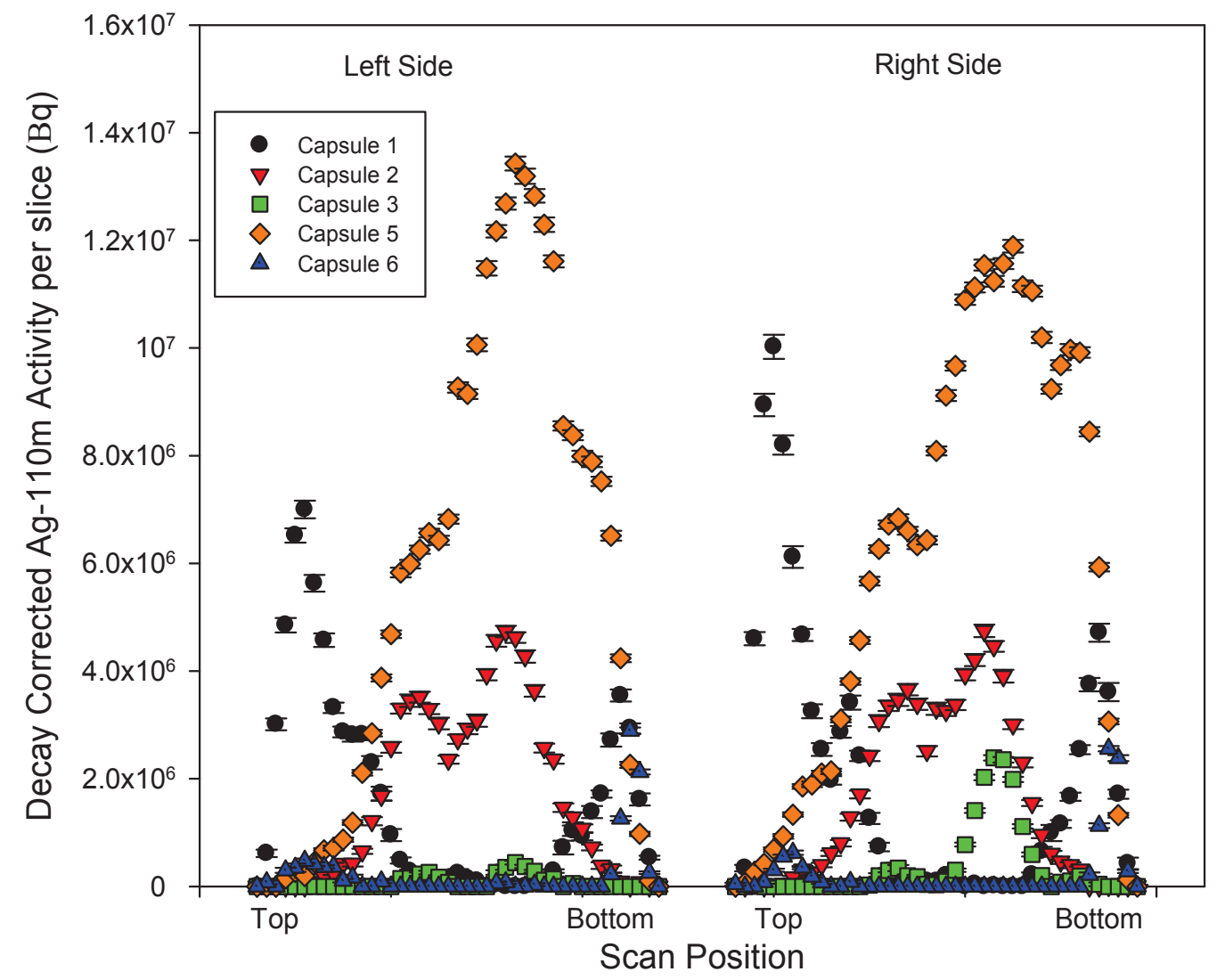

Figure 9. Axial distribution of Ag-110m in the AGR-1 graphite holders. 
The peaks seen in the Ag-110m axial profiles tend to be aligned with a vertical position that corresponds to the center of a fuel compact. Therefore, the transverse scans were performed with the collimator centered near the original axial location of a particular compact in the holder corresponding to the main peaks in measured activity. The Capsule 1 and 6 holders were scanned at Levels 1 and 4. Capsules 2 and 3 were scanned at Levels 2 and 3, and Capsule 5 was scanned at Levels 2, 3, and 4.

The transverse slice scans were processed to create pseudo-colored concentration maps of specific levels in the graphite holders. Decay-corrected Ag-110m activities from each lateral slice were first divided by the graphite volume seen through the collimator to yield volumetric concentrations in each slice. The Ag-110m concentrations at one azimuth were then multiplied by slice concentrations after a 90 degree rotation, producing a 12 by 12 matrix of Ag-110m concentration products. (Concentrations were multiplied rather than added for enhanced contrast.) The values for a specific level were then converted into pseudo colors using a 256-bit "cool-to-warm continuously diverging" colormap (Moreland 2009). A digital mask was then laid over the colored array to remove areas not present in the graphite holder. The process is described with additional detail in ECAR-1709 (Harp and Ploger 2011).

Highlights from the concentration maps are presented in this work, while all of the collected concentration maps are available in ECAR-1709 (Harp and Ploger 2011). Two representative concentration maps are shown in Figure 10, with Ag-110m concentrations (MBq per cubic $\mathrm{cm}$ ) displayed numerically adjacent to each slice on the horizontal and vertical axis and fuel compact identifiers shown within each hole in the mask. Note that relative concentration was mapped to color for individual maps; therefore, the colors on different maps cannot be compared directly. In Figure 9, the Ag-110m activity is higher on the right side of the Capsule 3 holder at Level 2, suggesting that Ag-110m is concentrated mostly about Stack 3. This conclusion is confirmed in the concentration map for Capsule 3 Level 2 (seen in Figure 10), where the transverse scans reveal Ag-110m concentrated about Stack 3. More generally, this concentration map reveals that the highest Ag-110m concentrations occurred on the holder periphery where the holder is closest to the capsule shell and the temperature was thus coolest. Silver also appeared to concentrate near the relatively cool molybdenum through tube at the bottom of Figure 10.
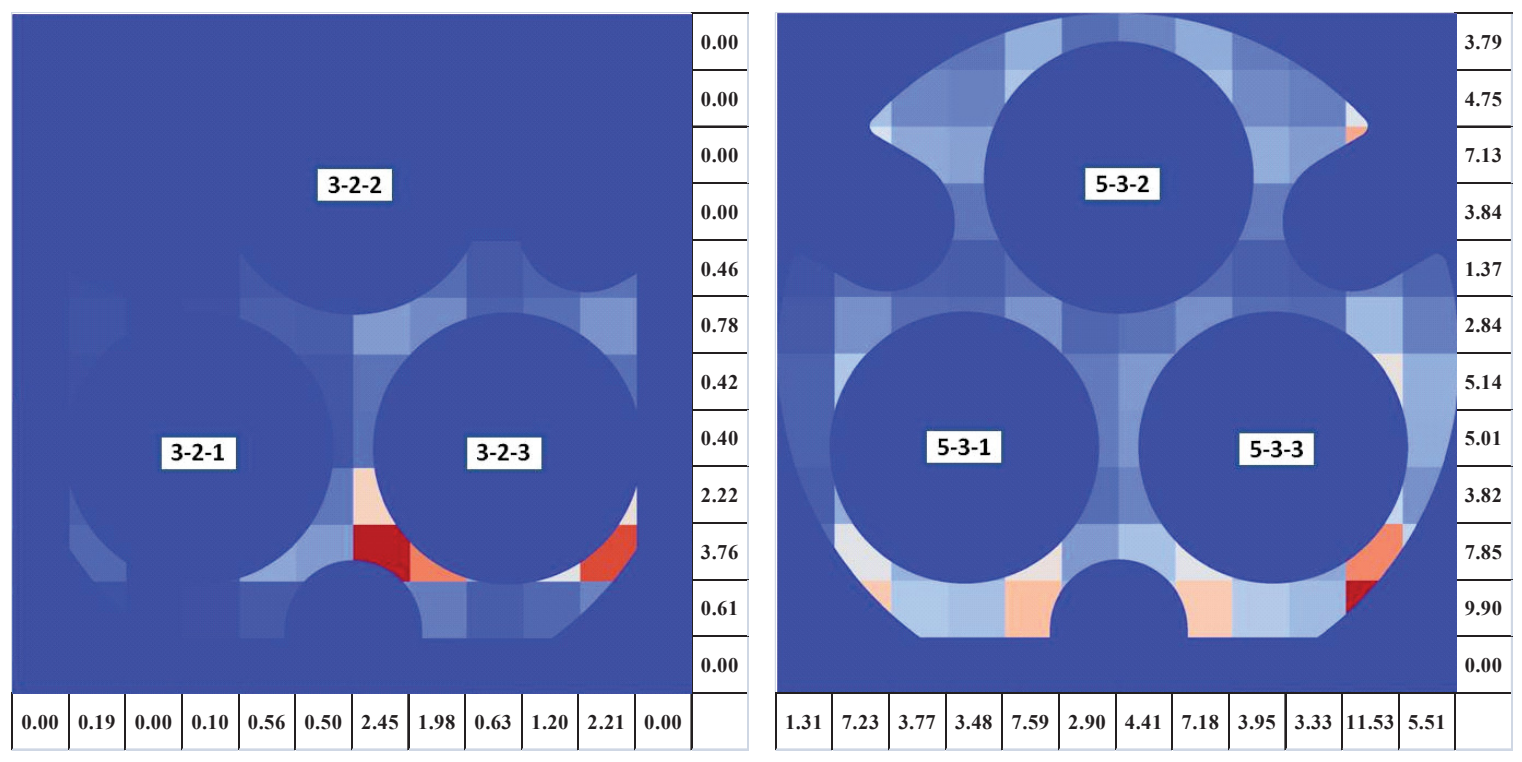

Figure 10. Relative Ag-110m concentration found in Holder 3, Level 2 (left) and Holder 5, Level 3 (right). The identification of specific compacts originally in these locations in the holders is provided.

For most regions in the holders that were examined with transverse gamma scans, there typically was a higher Ag-110m concentration around Stacks 1 and 3, which faced the center of the ATR core during 
irradiation, than around Stack 2, which experienced lower temperatures and lower neutron fluence than the other stacks. This general behavior is demonstrated in the Capsule 5, Level 3 map shown in Figure 10. This map also shows Ag-110m concentrated between Stack 1 and the capsule shell, between Stack 3 and the capsule shell, and near the molybdenum through tube groove at the bottom of the image.

In addition to Ag-110m, the spectra collected for the graphite holders were closely examined for evidence of other fission products. Both Cs-134 and Cs-137 were detected in Holder 5 and Holder 6. Cs-137 by itself is a poor indicator of fission product release from the fuel, given its long half life and prevalence as contamination in the hot cell due to other activities. One issue in identifying very small quantities of Cs-134 is interference from natural background peaks that are close in energy to the primary Cs-134 peak (about $37 \mathrm{kBq}(1 \mu \mathrm{Ci})$ ) is near the minimum detectable activity of Cs-134 in the gamma scanning system used for these experiments. This can result in Cs-134 detection by itself also being a poor indication of fission product release. However, detecting Cs-134 and Cs-137 together in a single spectrum in a decay-corrected proportion similar to that expected in the fuel is a good indication that the cesium originated from the AGR-1 fuel compacts.

The Cs-134 and Cs-137 activity in Holder 5 exhibits a strong peak centered at Level 2 in both of the axial scans of Holder 5 (Figure 11). The activity of both isotopes is well above the minimum detectable activity and both are clearly and consistently detectable over a large range. A Cs-134 intensity map was prepared from lateral scans of this level using the same technique applied to the Ag-110m measurements (shown in Figure 12). The activity intensity appears to be evenly distributed between the holes for Compact 5-2-1 and 5-2-3, suggesting that both compacts may have released cesium during irradiation. Both of these compacts were shipped to Oak Ridge National Laboratory for deconsolidation and analysis using the irradiated microsphere gamma analyzer (IMGA) to look for individual particles exhibiting evidence of in-pile cesium release. Preliminary results of this investigation are discussed in Section 3.2.

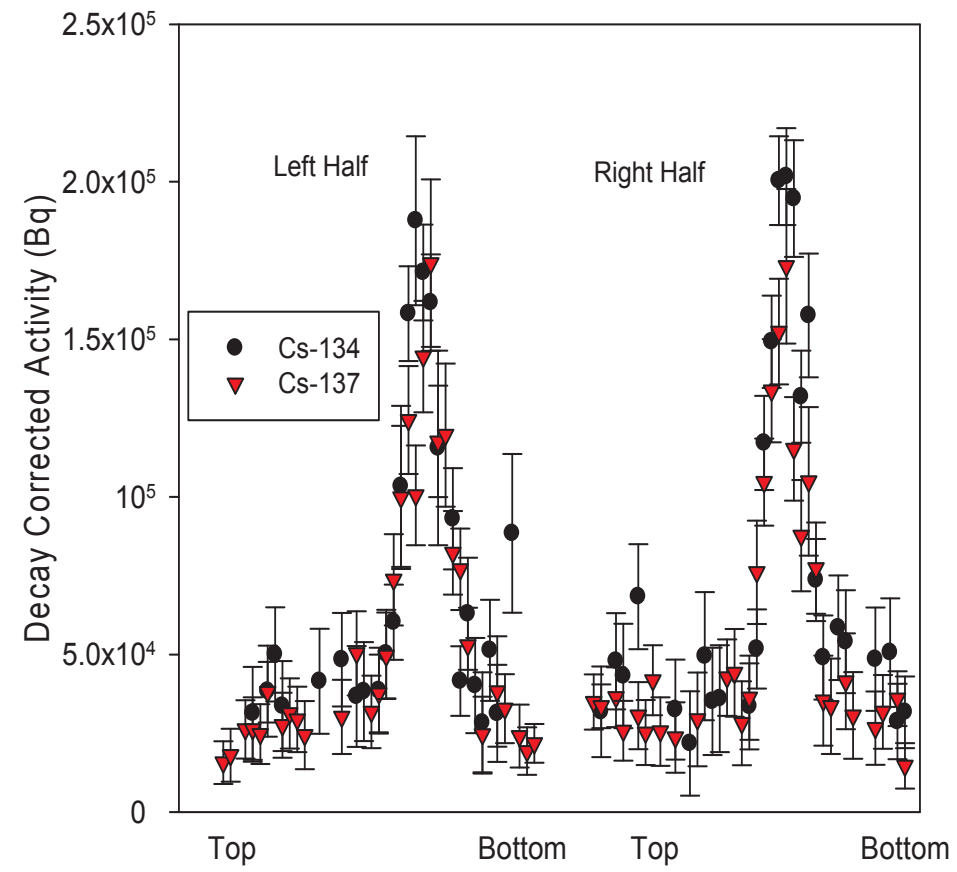

Figure 11. Axial distribution of Cs-134 and Cs-137 in the AGR-1 Capsule 5 graphite holder. 


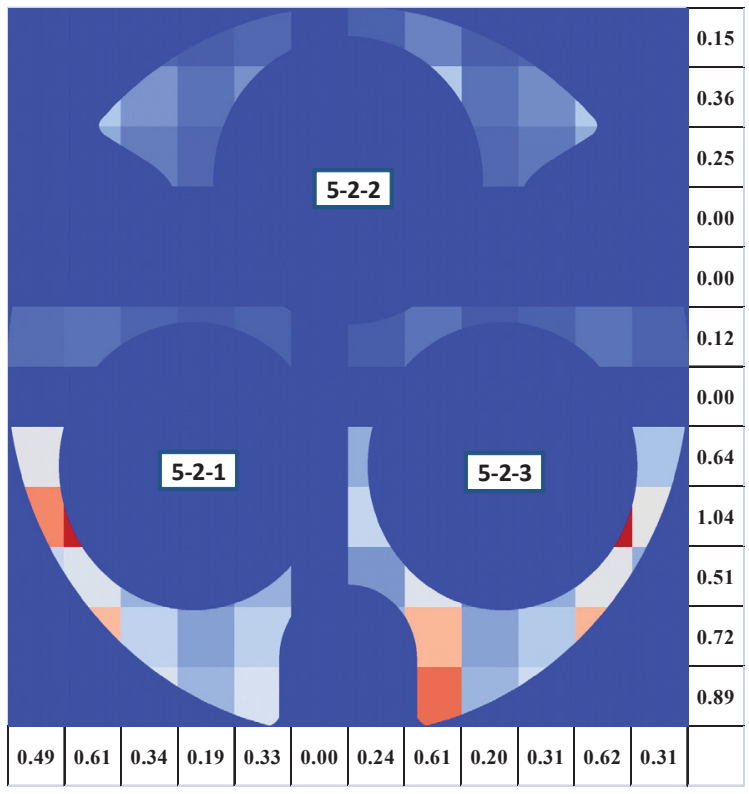

Figure 12. Cs-134 activity intensity map at Level 2 of the Capsule 5 graphite holder.

Spectra from Holder 6 also indicated a region of elevated Cs-134 and Cs-137 activity in the holder. The activities in this region were close to the minimum detectable activity, making the region less distinct than what was seen in Holder 5, but the consistent nature of the concurrent cesium activities indicate an activity concentration resulting from cesium released from the fuel. This region of the holder corresponded with the location of Compact 6-3-2 during irradiation. The average ratio of Cs-134 to Cs-137 over this region also roughly corresponds with the Cs-134 to Cs-137 activity ratio of 0.626 detected by the gamma scans of Compact 6-3-2 (Harp 2013). Details of the gamma scanning results for this graphite holder are discussed in Harp and Ploger (2011). Compact AGR-1 6-3-2 was deconsolidated and a leach-burn-leach procedure was performed (Demkowicz et al. 2012b). The burn-leach solution contained the approximate equivalent uranium inventory of a single kernel, indicating a particle with a defective or failed $\mathrm{SiC}$ layer was present in that particular compact. This result strongly suggests that the cesium hot spot found in Holder 6 was due to release from the particle in Compact 6-3-2 with a defective $\mathrm{SiC}$ layer. Note that the presence of a single particle with a defective $\mathrm{SiC}$ layer in Capsule 6 is consistent with pre-irradiation quality control data on SiC defect fractions for the AGR-1 fuel (Maki 2009).

Following the axial and transverse gamma scans described above, the graphite fuel holders were broken into pieces to retrieve the melt and fluence wire packages embedded in them. The pieces of the graphite holders where then loaded into containers (two containers were required for each graphite holder) that were transferred to the Analytical Laboratory hot cells for analysis on the same system used for the capsule shells described in Section 2.1. The calibration source for the pulverized compact holders was constructed using granulated activated carbon that was mixed with a known amount of multi-line gamma standard. This provided an energy and efficiency calibration from 59.4 to $1806 \mathrm{keV}$, with any matrix effects accounted for by the activated carbon. This approach allowed the inventory of gammaemitting fission products in the holders to be quantified with gamma spectrometry in a location where counting conditions were more favorable with much lower detection limits. This analysis also included Holder 4, which was inadvertently broken during disassembly and not gamma scanned previously. Table 3 contains the total decay-corrected measured activity and the fraction of the total predicted capsule inventory (based on calculated inventories in Sterbentz 2011) for all six AGR-1 holders. Several fission products had measureable activities in at least one of the holders, including Ag-110m, Ce-144, Cs-134, Cs-137, Eu-154, and Eu-155. 
Table 3. Decay-corrected measured activity and capsule inventory fraction for AGR-1 graphite fuel holders. Decay-Corrected Activity (Bq)

\begin{tabular}{cccccccc}
\hline Capsule & Ag-110m & Ce-144 & Cs-134 & Cs-137 & Eu-154 & Eu-155 & Sr-90 \\
6 & $1.86 \mathrm{E}+7$ & $9.10 \mathrm{E}+6$ & $4.17 \mathrm{E}+5$ & $1.48 \mathrm{E}+6$ & $1.82 \mathrm{E}+6$ & $1.02 \mathrm{E}+6$ & $2.49 \mathrm{E}+5$ \\
5 & $4.85 \mathrm{E}+8$ & $<2 \mathrm{E}+6$ & $2.28 \mathrm{E}+6$ & $3.38 \mathrm{E}+6$ & $7.99 \mathrm{E}+5$ & $5.53 \mathrm{E}+5$ & $9.73 \mathrm{E}+5$ \\
$4^{*}$ & $3.52 \mathrm{E}+8$ & $<2 \mathrm{E}+6$ & $<1 \mathrm{E}+5$ & $<3 \mathrm{E}+5$ & $6.13 \mathrm{E}+5$ & $<3 \mathrm{E}+5$ & $1.02 \mathrm{E}+4$ \\
3 & $1.70 \mathrm{E}+7$ & $<9 \mathrm{E}+5$ & $<1 \mathrm{E}+5$ & $4.76 \mathrm{E}+5$ & $7.26 \mathrm{E}+5$ & $6.42 \mathrm{E}+5$ & $1.92 \mathrm{E}+5$ \\
2 & $1.38 \mathrm{E}+8$ & $<1 \mathrm{E}+6$ & $<1 \mathrm{E}+5$ & $1.32 \mathrm{E}+6$ & $6.56 \mathrm{E}+5$ & $6.52 \mathrm{E}+5$ & $1.05 \mathrm{E}+5$ \\
1 & $1.45 \mathrm{E}+8$ & $<7 \mathrm{E}+5$ & $1.03 \mathrm{E}+5$ & $1.81 \mathrm{E}+6$ & $4.88 \mathrm{E}+5$ & $4.20 \mathrm{E}+5$ & $4.41 \mathrm{E}+6$ \\
\hline \multicolumn{7}{c}{ Capsule Fraction } \\
\hline Capsule & Ag-110m & Ce-144 & Cs-134 & Cs-137 & Eu-154 & Eu-155 & Sr-90 \\
6 & $1.64 \mathrm{E}-2$ & $4.08 \mathrm{E}-6$ & $2.99 \mathrm{E}-6$ & $8.95 \mathrm{E}-6$ & $3.71 \mathrm{E}-4$ & $2.77 \mathrm{E}-4$ & $1.70 \mathrm{E}-6$ \\
5 & $2.17 \mathrm{E}-1$ & $<8 \mathrm{E}-7$ & $9.90 \mathrm{E}-6$ & $1.67 \mathrm{E}-5$ & $1.06 \mathrm{E}-4$ & $1.02 \mathrm{E}-4$ & $5.62 \mathrm{E}-6$ \\
$4^{*}$ & $1.16 \mathrm{E}-1$ & $<9 \mathrm{E}-7$ & $<4 \mathrm{E}-7$ & $<1 \mathrm{E}-6$ & $6.74 \mathrm{E}-5$ & $<5 \mathrm{E}-5$ & $5.50 \mathrm{E}-8$ \\
3 & $5.13 \mathrm{E}-3$ & $<3 \mathrm{E}-7$ & $<4 \mathrm{E}-7$ & $2.09 \mathrm{E}-6$ & $7.58 \mathrm{E}-5$ & $9.35 \mathrm{E}-5$ & $1.01 \mathrm{E}-6$ \\
2 & $4.94 \mathrm{E}-2$ & $<5 \mathrm{E}-7$ & $<4 \mathrm{E}-7$ & $6.06 \mathrm{E}-6$ & $7.53 \mathrm{E}-5$ & $1.04 \mathrm{E}-4$ & $5.73 \mathrm{E}-7$ \\
1 & $8.64 \mathrm{E}-2$ & $<3 \mathrm{E}-7$ & $5.24 \mathrm{E}-7$ & $9.51 \mathrm{E}-6$ & $7.42 \mathrm{E}-5$ & $8.78 \mathrm{E}-5$ & $2.67 \mathrm{E}-5$ \\
\hline
\end{tabular}

* Substantial graphite was lost from Holder 4 during disassembly, with estimates indicating as much as $15 \%$. The values provided here have not been corrected for mass loss.

After the holders were gamma counted, an analysis of Sr-90 and other non-gamma-emitting isotopes was still required. The proposed approach was to oxidize the holders in air, leach the residue with nitric acid, and analyze the solutions with mass spectrometry and with a gas flow proportional counter after performing a chemical separation to isolate the strontium. Various difficulties were encountered during the oxidation and leaching of the holders, which resulted in numerous procedural changes as the work progressed and slightly different processing conditions for the various holders. It ultimately was concluded that the addition of boron carbide to the holders at nominal loadings of $5.5 \mathrm{wt} \%$ (Capsules 1 and 6) and $7.0 \mathrm{wt} \%$ (Capsules 2 through 5) severely inhibited the oxidation of the graphite. This most likely was due to both the formation of lithium carbide (the lithium resulting from the $\left.{ }^{10} \mathrm{~B}(n, \alpha)\right)^{7} \mathrm{Li}$ reaction during irradiation) and from the remaining ${ }^{11} \mathrm{~B}_{4} \mathrm{C}$ that was not converted during irradiation. Details of the processing approach for each graphite holder are given in the appendix. The results for Sr-90 are provided in Table 3.

The capsule fraction of Ag-110m in the holders is significant and extends over a large range, from $5.1 \times 10^{-3}$ to $2.2 \times 10^{-1}$. The Ag- $110 \mathrm{~m}$ activities measured by gamma counting the broken holders agree well with the Ag-110m activities determined by summing the activities from each slice of the axial gamma scans (Figure 9). The largest discrepancy between the two sets of measurements is $5.7 \%$. While the original intent of gamma scanning was to determine relative spatial distributions in the holders, this comparison indicates that the method also is capable of reasonably accurate quantitative data.

Measureable quantities of Cs-134 and Cs-137 were detected in Holders 1, 5, and 6, although the amount in Holder 1 was very close to the detection limit. The elevated total inventories in Holders 5 and 6 are in agreement with the findings from gamma scanning of these components, which indicated specific locations with elevated cesium activity.

The europium isotopes Eu-154 and Eu-155 also were present in the holders. The inventories of Eu-154 in Table 3 (which in all cases exceed the inventory of a single kernel) indicate that europium was released through intact coatings, although to a much lesser extent than silver. The fraction of Sr-90 in the graphite holders varied considerably, from $5.5 \times 10^{-8}$ to $2.7 \times 10^{-5}$. As noted in the appendix, variations in 
the efficiency of strontium recovery from the graphite holders during the leach processes could result in uncertainties in the values in Table 3.

Ce-144 activity in the holders was usually very low and close to the detection limit of the gamma counting system. The exception was Capsule 6 , which contained a capsule fraction of $4 \times 10^{-6}$, which is well below the inventory of a single particle. The relatively large Ce-144 inventory in Holder 6 may be related to the particle with a defective $\mathrm{SiC}$ layer in Compact 6-3-2, or it may be a result of the temperature in Capsule 6, which was the hottest capsule on average.

As discussed in the appendix, Pd-105 was found in relatively significant amounts in Holders 1 and 2 (representing a capsule fraction of approximately $10^{-2}$ and $10^{-3}$, respectively), while no Pd-105 was detected in the leach solutions from any of the other holders. This suggests that palladium is being released from intact coatings and is migrating to the graphite holders, but that the analysis technique used gave inconsistent results, making comparison of results from the various graphite holders problematic.

\subsection{Graphite Spacers and Grafoil Disks}

The graphite spacers and Grafoil disks (shown in orange in Figure 1 and collectively referred to here as the graphite spacers) acted as caps to hold the fuel compacts in their proper axial alignment during the test and provide thermal insulation at the axial ends of the capsules. The spacers and disks for each capsule were removed from the test train, placed in plastic containers, and sent to the Analytical Laboratory for analysis using gamma spectrometry. The detector system used was an HPGe coaxial detector, ORTEC Model GEM40195, located outside the hot cell inside a steel vault with approximately 10 -in. thick walls to provide shielding. The detector was calibrated using a solution with a known activity of several gamma-emitting isotopes absorbed in filter paper that corresponded to the geometry of the spacers. The calibrated energy range for the detector was 59.4 to $1,836 \mathrm{keV}$. Detectable quantities of Ag-110m, Cs-134, Cs-137, and Ce-144 were measured in the spacers. The decay-corrected activities and total capsule inventory fractions are shown in Table 4 . The fractions shown in Table 4 for Cs-134, Cs-137, and Ce-144 represent less than 1 particle inventory. There is a relatively higher amount of Ag-110m present in the spacers from Capsules 1 and 6. This follows trends observed in the graphite holders.

\subsection{Gas Exit Lines}

The niobium gas exit lines from the fueled portion of the AGR-1 test train were saved during capsule disassembly for analysis of fission products released from the fuel and deposited inside the lines. The original plan for gas line analysis involved coiling each line around a spindle, sending the intact gas lines to the Analytical Laboratory, and flushing all activity from the interior of the lines with a nitric acid solution for subsequent measurement. However, during capsule disassembly it was discovered that the gas lines were extremely brittle and would not support the handling required to transport them intact to the Analytical Laboratory. As an alternative approach, the gas lines from the fueled section were cut into approximately $2.5-\mathrm{cm}$ segments, which were placed in separate plastic vials that were transferred to the Analytical Laboratory for gamma spectrometry. A special stage was constructed to elevate gas exit lines $60 \mathrm{~cm}$ above the detector, and each segment was placed into a scintillation vial to control geometry and contamination. The same HPGe detector used to analyze the graphite spacers (Section 2.3) was used for the gas lines. The detector efficiency for the gas exit lines was calibrated using a 1.0-mL, multi-line gamma-ray source with energies ranging from 59.4 to $1,836 \mathrm{keV}$. The source was pipetted into a borosilicate scintillation vial. At $60 \mathrm{~cm}$ this geometry was considered similar to the geometry of the gas exit lines. A total of 41 of the $2.5-\mathrm{cm}$ segments were counted, representing portions of the gas lines from Capsules 1 through 5 (no gas exit line segments from Capsule 6 were available because the test train was sectioned immediately above Capsule 6). The dominant radionuclides in the lines were found to be Nb-94 
and Nb-95 (average Nb-94 activity in the 2.5-cm segments was about 8,140 kBq); both are the result of neutron activation of $\mathrm{Nb}-93$.

Table 4. Decay-corrected activity and capsule inventory fraction of gamma-emitting fission products in the graphite spacers and Grafoil disks from the AGR-1 capsules.

Decay-Corrected Activity (Bq)

\begin{tabular}{ccccc}
\hline Capsule & Ag-110m & Cs-134 & Cs-137 & Ce-144 \\
6 & $1.63 \mathrm{E}+07$ & $3.12 \mathrm{E}+04$ & $4.13 \mathrm{E}+04$ & $3.30 \mathrm{E}+06$ \\
5 & $3.69 \mathrm{E}+05$ & $5.30 \mathrm{E}+03$ & $1.18 \mathrm{E}+04$ & $8.56 \mathrm{E}+03$ \\
4 & $8.36 \mathrm{E}+04$ & $2.16 \mathrm{E}+04$ & $2.59 \mathrm{E}+04$ & $2.91 \mathrm{E}+05$ \\
3 & $2.24 \mathrm{E}+04$ & $1.25 \mathrm{E}+04$ & $1.68 \mathrm{E}+04$ & $1.38 \mathrm{E}+05$ \\
2 & $3.01 \mathrm{E}+04$ & $7.57 \mathrm{E}+03$ & $2.22 \mathrm{E}+04$ & $5.11 \mathrm{E}+04$ \\
1 & $1.27 \mathrm{E}+07$ & $\mathrm{ND}$ & $5.02 \mathrm{E}+04$ & $2.55 \mathrm{E}+05$ \\
\hline \multicolumn{5}{c}{ Capsule Fraction } \\
\hline Capsule & $\mathbf{A g}-110 m$ & Cs-134 & Cs-137 & Ce-144 \\
6 & $1.45 \mathrm{E}-02$ & $2.24 \mathrm{E}-07$ & $2.49 \mathrm{E}-07$ & $1.48 \mathrm{E}-06$ \\
5 & $1.65 \mathrm{E}-04$ & $2.30 \mathrm{E}-08$ & $5.83 \mathrm{E}-08$ & $3.35 \mathrm{E}-09$ \\
4 & $2.74 \mathrm{E}-05$ & $7.40 \mathrm{E}-08$ & $1.17 \mathrm{E}-07$ & $1.11 \mathrm{E}-07$ \\
3 & $6.76 \mathrm{E}-06$ & $4.02 \mathrm{E}-08$ & $7.36 \mathrm{E}-08$ & $5.20 \mathrm{E}-08$ \\
2 & $1.08 \mathrm{E}-05$ & $2.73 \mathrm{E}-08$ & $1.02 \mathrm{E}-07$ & $1.95 \mathrm{E}-08$ \\
1 & $7.55 \mathrm{E}-03$ & N/A & $2.64 \mathrm{E}-07$ & $1.06 \mathrm{E}-07$ \\
\hline
\end{tabular}

The only fission product that was detected in any of the line segments was Ag-110m and in all cases the detected activity was very low and very close to the detection limit. The results for Ag-110m for each AGR-1 capsule are summarized in Table 5, where the measured Ag-110m activity has been decay-corrected and converted to a fraction of the total predicted capsule inventory (based on data in Sterbentz 2011). Values in Table 5 preceded by "<" indicate that no Ag-110m was detected and the minimum detectable activity of the measurement was used to calculate the capsule fraction provided. In Table 5, the "Position" refers to the segment of the gas exit line, starting at the top of the capsule head and increasing upward (i.e., position 1 was the first segment above the capsule head, position 2 was the second segment, etc.). As indicated in the table, there were different total lengths of gas lines recovered from each capsule because of their location in the test train. Segments in the table that are shaded blue have been analyzed and the values are provided in the table; segments shaded green were sectioned in the hot cell but were not analyzed. For Capsules 2, 4, and 5, Ag-110m was only detected in the segment of the gas line immediately adjacent to the capsule (position 1). In Capsule 3, Ag-110m was detected further from the capsule, but the quantity detected is very near the minimum detectable activity. No Ag-110m was detected in the gas line from Capsule 1.

No activity from any other fission products was detected in the gas line segments measured. The average minimum detectable activities for all gas line segments and the corresponding average capsule fraction for four key fission products are given in Table 6 . Because of the low and usually unquantifiable activity of fission products in the gas exit lines, it was determined that the remaining gas exit line segments would not be analyzed. In addition, because of the very small inventory of fission products in the gas lines relative to the much larger contributions from the other capsule components, the gas exit line data have been neglected in the discussion of total capsule mass balance in subsequent sections of this report. 
It should be noted that iodine is probably the most volatile condensable fission product that could have been released from the fuel and transported to the gas exit lines. However, the long-lived isotopes of iodine (I-129 and I-127) cannot be detected with gamma spectrometry and would require chemical detection measurements. After each irradiation cycle in the ATR, a measurement was performed to determine the fraction of I-135 outside of the fuel. These measurements indicate the release fraction for I135 is less than $10^{-7}$ (Scates et al. 2010, Hartwell et al. 2007). Assuming the release of I-135 is similar to the release of other radioiodine isotopes, there is insufficient evidence to suggest a detectable amount of iodine (fractional release approximately $10^{-6}$ ) migrated to the gas exit lines to justify a chemical evaluation of I-127 or I-129.

Table 5. Capsule fraction of Ag-110m measured in gas exit line segments. Segments represented by blue cells have been gamma counted. Segments represented by green cells were prepared but were not counted.

\begin{tabular}{|c|c|c|c|c|c|c|}
\hline Position & Capsule 5 & Capsule 4 & Capsule $3 a^{*}$ & Capsule $3 b^{*}$ & Capsule 2 & Capsule 1 \\
\hline 1 & $5.9 \times 10^{-5}$ & $8.4 \times 10^{-6}$ & & & $5.3 \times 10^{-5}$ & $<3 \times 10^{-5}$ \\
\hline 2 & $<1 \times 10^{-5}$ & $<7 \times 10^{-6}$ & & & $<2 \times 10^{-5}$ & $<3 \times 10^{-5}$ \\
\hline 3 & $<9 \times 10^{-6}$ & $<7 \times 10^{-6}$ & & & $<7 \times 10^{-6}$ & $<3 \times 10^{-5}$ \\
\hline 4 & $<8 \times 10^{-6}$ & $<7 \times 10^{-6}$ & $<7 \times 10^{-6}$ & & $<2 \times 10^{-5}$ & \\
\hline 5 & $<9 \times 10^{-6}$ & $<7 \times 10^{-6}$ & $<1 \times 10^{-5}$ & & $<2 \times 10^{-5}$ & \\
\hline 6 & $<7 \times 10^{-6}$ & & $<1 \times 10^{-5}$ & & $<2 \times 10^{-5}$ & \\
\hline 7 & & & $<1 \times 10^{-5}$ & & $<2 \times 10^{-5}$ & \\
\hline 8 & & & $<1 \times 10^{-5}$ & & & \\
\hline 9 & & & $<1 \times 10^{-5}$ & & & \\
\hline 10 & & & $<1 \times 10^{-5}$ & & & \\
\hline 11 & & & $<1 \times 10^{-5}$ & & & \\
\hline 12 & & & $<1 \times 10^{-5}$ & & & \\
\hline 13 & & & $7.4 \times 10^{-6}$ & & & \\
\hline 14 & & & & & & \\
\hline 15 & & & & & & \\
\hline 16 & & & & $<7 \times 10^{-6}$ & & \\
\hline 17 & & & & $<4 \times 10^{-6}$ & & \\
\hline 18 & & & & $<1 \times 10^{-5}$ & $<2 \times 10^{-5}$ & \\
\hline 19 & & & & & $<9 \times 10^{-6}$ & \\
\hline 20 & & & & & $<9 \times 10^{-6}$ & \\
\hline 21 & & & & & $<9 \times 10^{-6}$ & \\
\hline 22 & & & & & $<9 \times 10^{-6}$ & \\
\hline 23 & & & & & $<9 \times 10^{-6}$ & \\
\hline 24 & & & & & $<9 \times 10^{-6}$ & \\
\hline 25 & & & & & & \\
\hline 26 & & & & & & \\
\hline 27 & & & & & & \\
\hline 28 & & & & & & \\
\hline 29 & & & & & & \\
\hline
\end{tabular}

* The gas inlet and exit lines (both about 18-in. long) from Capsule 3 could not be distinguished during disassembly; therefore, both have been included in the analysis. 
Table 6. Average minimum detectable activity for selected isotopes taken from the reported limits of all gas line segments for which the isotope was not detected.

Average Minimum Detectable Activity

\begin{tabular}{ccc} 
Isotope & $(\mathrm{Bq})$ & Capsule Fraction \\
\hline Ag-110m & $5 \times 10^{3}$ & $1 \times 10^{-5}$ \\
Cs-134 & $6 \times 10^{3}$ & $4 \times 10^{-8}$ \\
Cs-137 & $1 \times 10^{4}$ & $6 \times 10^{-8}$ \\
Eu-154 & $4 \times 10^{3}$ & $5 \times 10^{-7}$ \\
\hline
\end{tabular}

\subsection{Capsule Silver Mass Balance}

Fifty-six of the 72 AGR-1 compacts were gamma scanned to quantify the relatively low Ag-110m inventory and the results are detailed in ECAR-1682 (Harp 2013). The summary results are provided in Figure 13, which shows the retained fraction of Ag-110m in each compact measured. Retained fraction is the ratio of the measured inventory in the compact to the predicted inventory based on physics simulations (Sterbentz 2011).

With the measured Ag-110m inventory in the compacts combined with the inventory measured in the various capsule components, a comprehensive Ag-110m mass balance for each of the capsules can be computed. For capsules in which Ag-110m data were not available for certain compacts (some compacts were unavailable for gamma scanning because they had been previously consumed in PIE experiments), the retention of the missing compacts was assumed to be the average retention fraction of the measured compacts in that capsule. The results of the Ag-110m mass balance are shown graphically in Figure 14, where the fraction of the total predicted capsule inventory is provided for the four main components: fuel compacts, metal capsule components, graphite fuel holders, and graphite spacers. The total percent of Ag-110m activity accounted for in each capsule is provided at the top of the chart in red. Values slightly greater than $100 \%$ indicate that the predicted Ag-110m inventory in the capsule is slightly low or that the measured values are biased high.

The results for Capsule 3 and, to a slightly lesser extent, Capsule 2 are a good indication that the predicted Ag-110m inventories (Sterbentz 2011) are reasonably accurate. Because very little of the silver in these capsules was released from the compacts to the capsule components, it is not likely that the total mass balance was significantly biased by the loss of any silver during capsule component analysis (i.e., silver that might be lost during capsule shell leaching to recover deposited fission products). In five of the six capsules, the total mass balance is within $11 \%$ of the predicted inventory. The conspicuously low total in Capsule 6 could be influenced by several factors. It is clear from existing data (including compact burnup measurements in Harp [2013]) that the physics simulations tend to over-predict burnup at the top of Capsule 6. This would result in an artificially high value for the Ag-110m inventory in simulations and result in a lower total mass balance. Also, Capsule 6 apparently exhibited the largest amount of silver released to the capsule components; therefore, any systematic errors in recovering silver from the components or quantifying silver would likely be greatest with this capsule. 


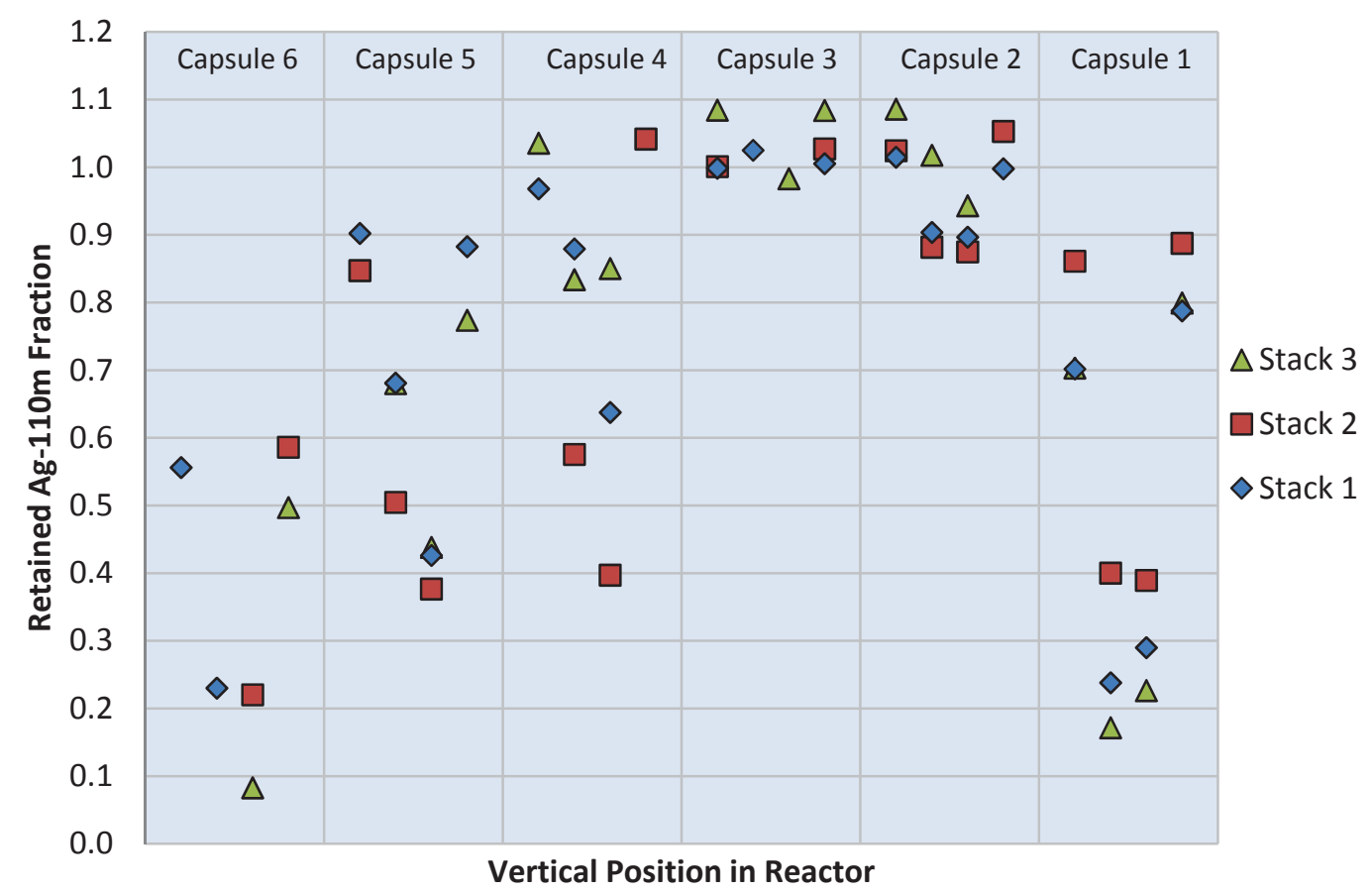

Figure 13. Retained Ag-110m fraction for AGR-1 compacts.

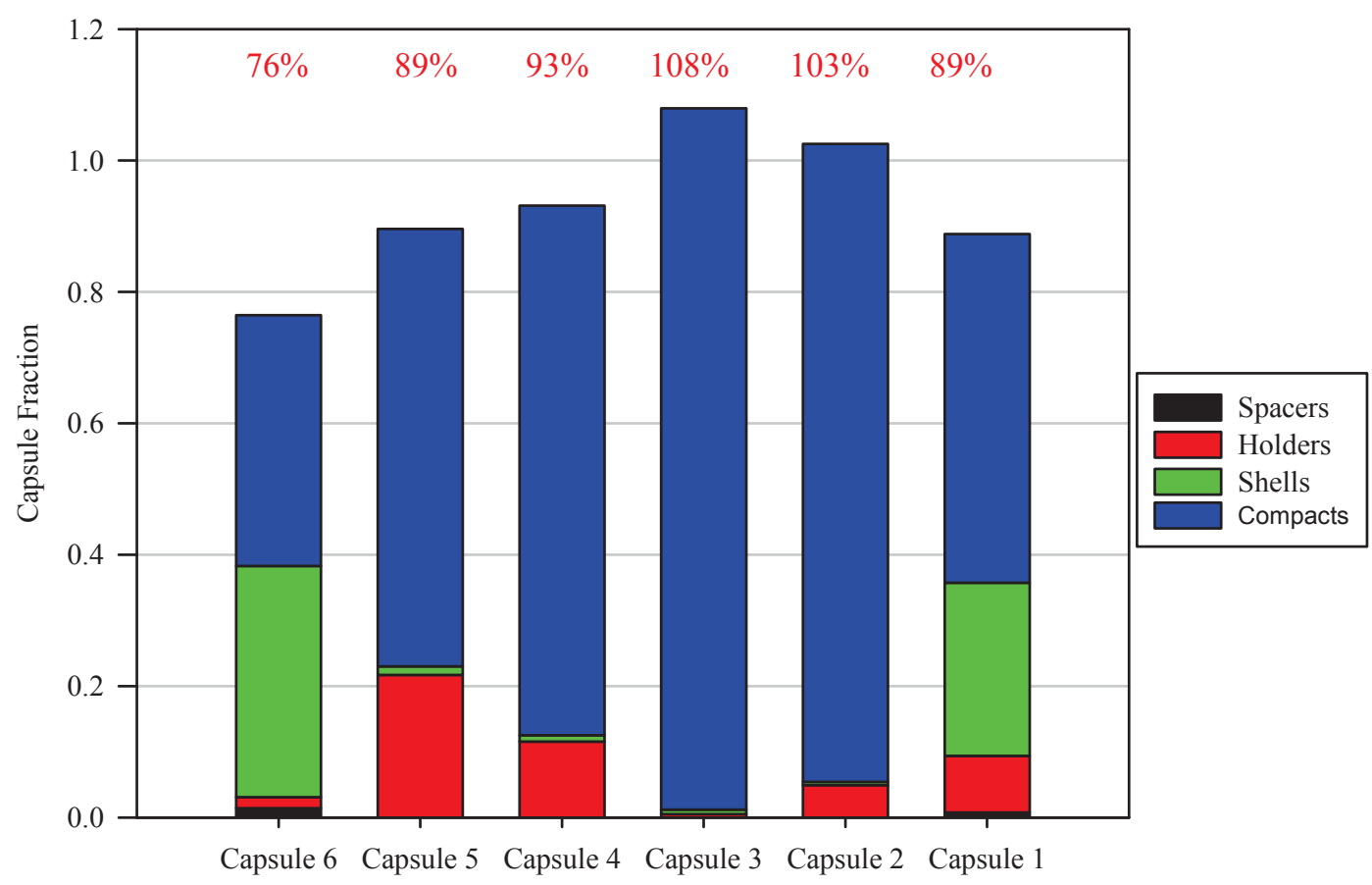

Figure 14. Fraction of predicted total capsule Ag-110m inventory found in the compacts, on the metal capsule components ("shells"), the graphite spacers, and the graphite holder for each capsule. The total percent of the predicted inventory accounted for is listed at the top of each column. 


\section{DISCUSSION}

The total fractional inventories of key fission products in all of the components for each AGR-1 capsule are given in Table 7. This includes contributions from the metallic components, the graphite holders, and the graphite spacers for each capsule (except for Sr-90, for which only the metallic components and the graphite holders are included). The contribution from the gas exit lines has not been included because the detected activity was negligible. As with the data in Section 2, the fractional inventory is calculated by dividing the measured activity by the predicted activity for the entire capsule, based on data in Sterbentz (2011). Figure 15 through Figure 18 present the total capsule fraction of Cs-134, Eu-154, Ag-110m, and Sr-90 found in each capsule, broken down by contribution from the three primary capsule components (note that Cs-134 is used here instead of Cs-137, since measurement of this isotope is less susceptible to interference from hot cell contamination and the data are therefore considered to be a more reliable indication of cesium released from the fuel). If no activity was detected in a particular component, the minimum detectable activity was used to calculate an equivalent fractional inventory and was included in the totals in Table 7. The data from these components are represented by cross-hatched columns in Figure 15 and Figure 16. If the contribution from components without detectable activity was greater than $50 \%$ of the total for a particular capsule, then the value is preceded by " $<$ " in Table 7; these values constitute an upper bound on the actual capsule fraction. It is assumed that the experiments presented here have effectively accounted for the total inventory of the major fission products released from the compacts to the capsule components and therefore represent the total fractional release from the compacts in each capsule.

Table 7. Total fractional inventory of selected fission products found in the AGR-1 capsule components.

\begin{tabular}{ccccc} 
Capsule & Ag-110m & Cs-134 & Eu-154 & Sr-90 \\
\hline 6 & $3.8 \mathrm{E}-1$ & $1.33 \mathrm{E}-5$ & $4.75 \mathrm{E}-4$ & $3.15 \mathrm{E}-06$ \\
5 & $2.3 \mathrm{E}-1$ & $1.22 \mathrm{E}-5$ & $1.43 \mathrm{E}-4$ & $7.14 \mathrm{E}-06$ \\
4 & $1.3 \mathrm{E}-1$ & $<2.4 \mathrm{E}-6$ & $<1.4 \mathrm{E}-4$ & $9.75 \mathrm{E}-06$ \\
3 & $1.2 \mathrm{E}-2$ & $<2.5 \mathrm{E}-6$ & $4.46 \mathrm{E}-4$ & $2.20 \mathrm{E}-06$ \\
2 & $5.5 \mathrm{E}-2$ & $<1.2 \mathrm{E}-6$ & $1.65 \mathrm{E}-4$ & $8.42 \mathrm{E}-07$ \\
1 & $3.6 \mathrm{E}-1$ & $<2.8 \mathrm{E}-6$ & $1.30 \mathrm{E}-4$ & $2.84 \mathrm{E}-05$ \\
\hline
\end{tabular}

Note that a fraction of $2 \mathrm{E}-5$ represents a single particle inventory. 


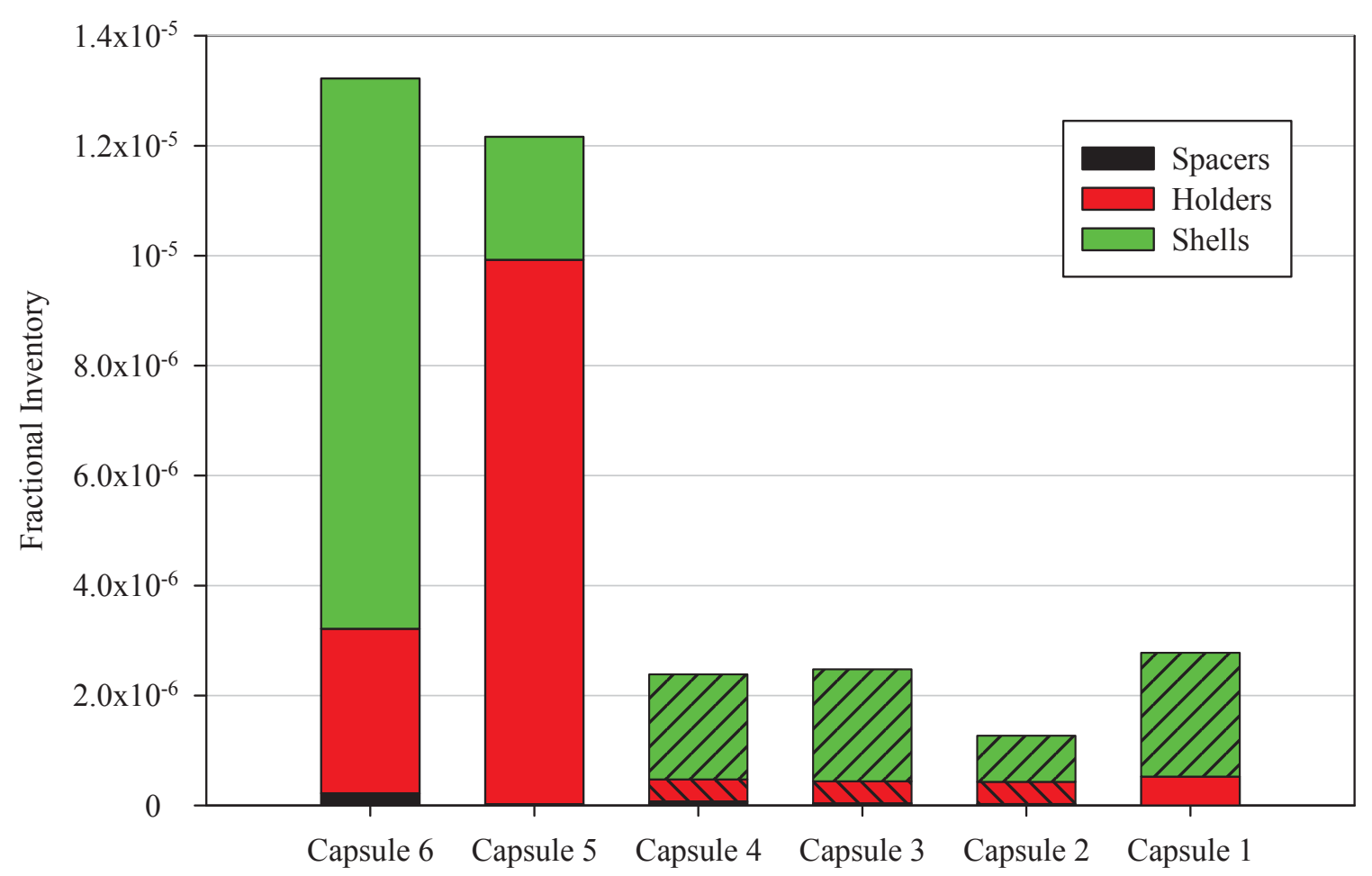

Figure 15. Fractional inventory of Cs-134 in the AGR-1 capsules components.

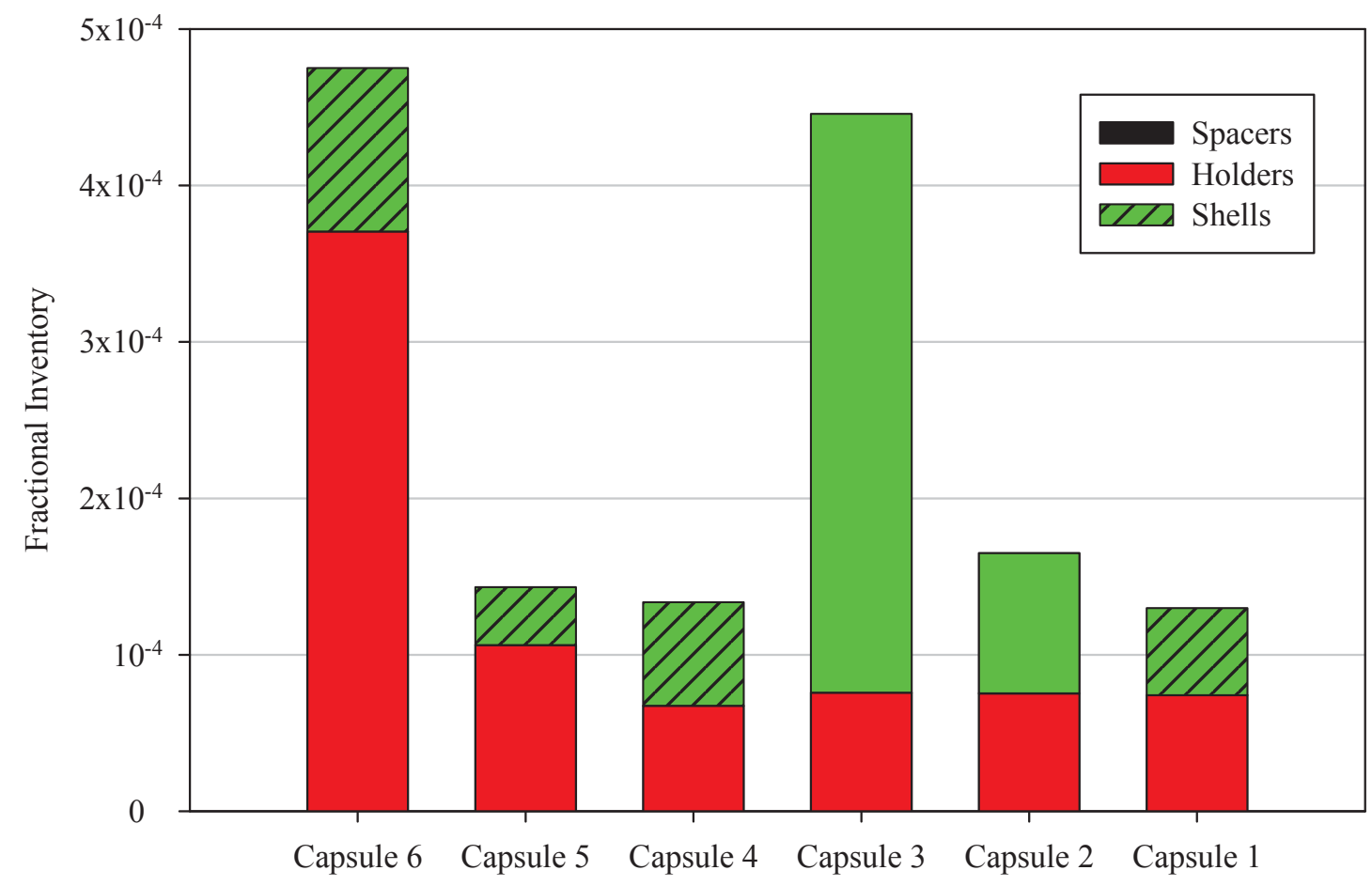

Figure 16. Fractional inventory of Eu-154 in the AGR-1 capsule components. 


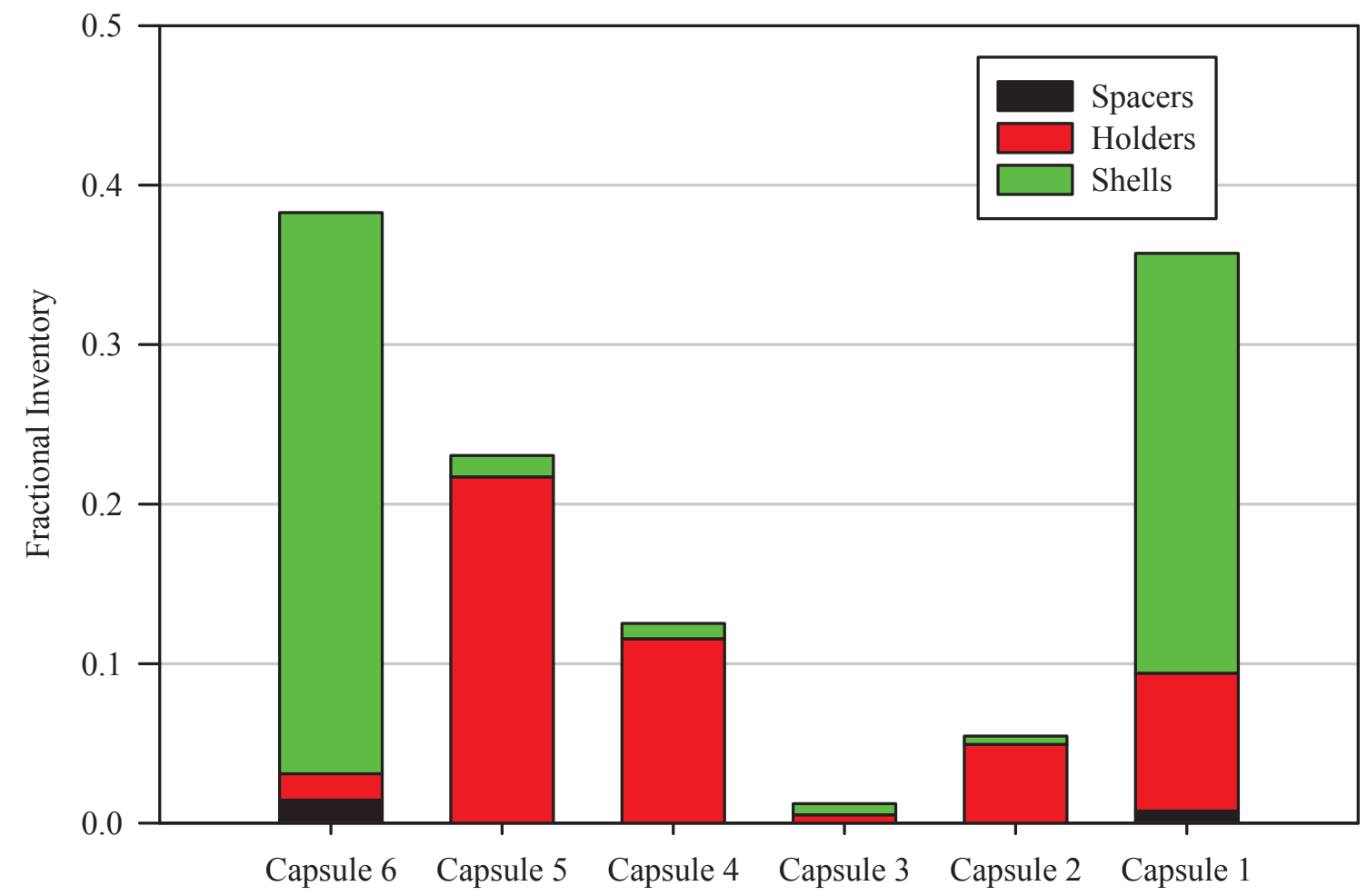

Figure 17. Fractional inventory of $\mathrm{Ag}-110 \mathrm{~m}$ in the AGR-1 capsule components.

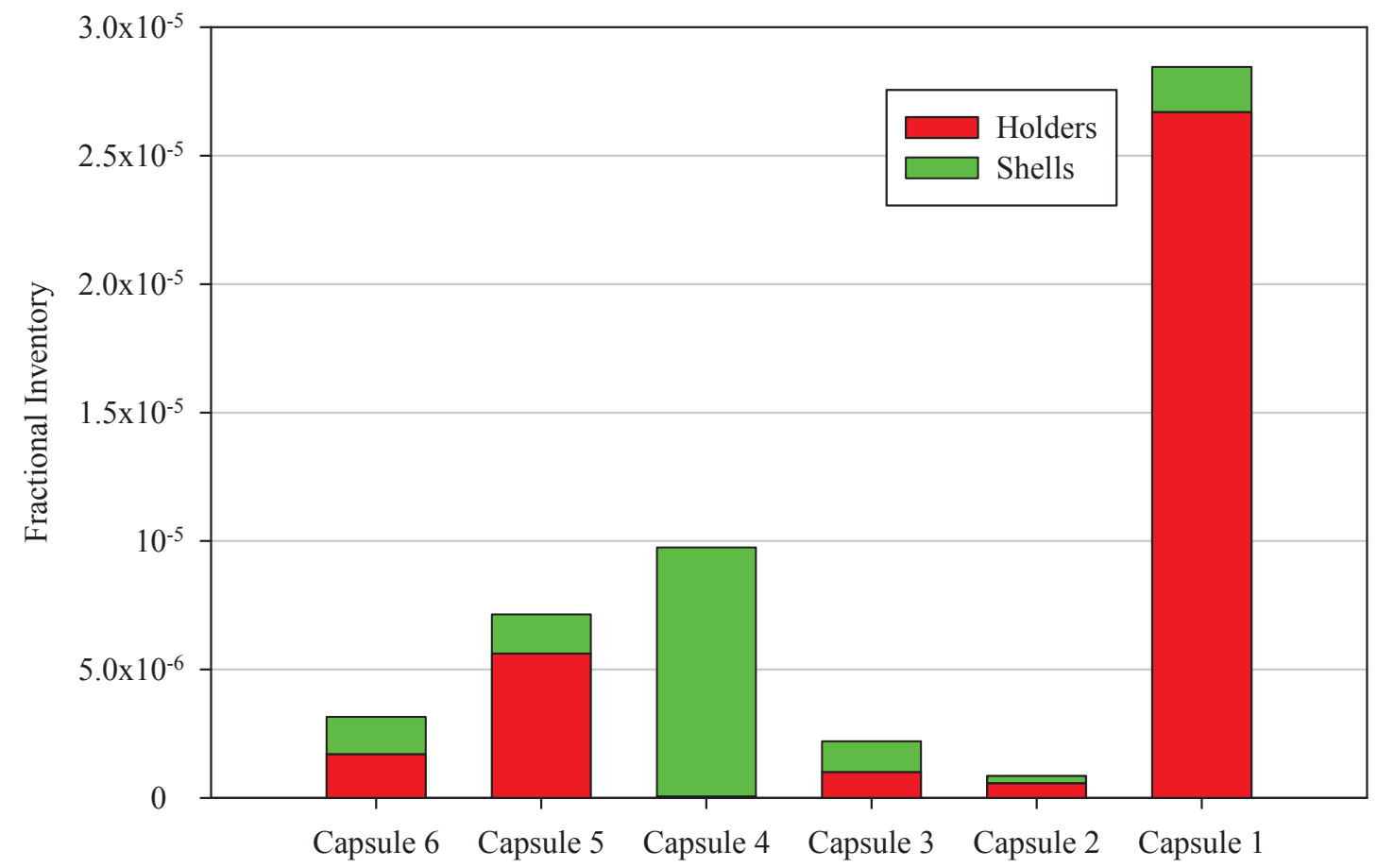

Figure 18. Fractional inventory of Sr-90 in the AGR-1 capsule components. 


\subsection{Silver}

The release of Ag-110m from the compacts ranges from $1.2 \times 10^{-2}$ (Capsule 3 ) to $3.8 \times 10^{-1}$ (Capsule 6), indicating significant release through intact $\mathrm{SiC}$ coatings in all capsules. The release was highest at the ends of the test train (Capsules 1 and 6). It is noteworthy that the majority of Ag-110m in the outer Capsules 1 and 6 was found on the capsule shells, while the majority on the inner capsules (Capsules 2 through 5) was found in the graphite holder. It is possible that this behavior is related to compact and capsule temperatures during irradiation. It also is possible that this behavior is related to the effective temperature control gap between the graphite holders and the steel capsule shells during irradiation, which was distinctly different in Capsules 1 and 6 relative to the other capsules. All of the holders initially contained boron carbide as a burnable poison, with Holders 1 and 6 containing nominally 5.5\% $\mathrm{B}_{4} \mathrm{C}$ and Holders 2 through 5 containing nominally $7.0 \% \mathrm{~B}_{4} \mathrm{C}$. During post-irradiation measurements of graphite holder dimensions, it was found that Holders 1 and 6 had experienced net diametrical shrinkage, while Holders 2, 3, and 5 (and presumably Holder 4) had experienced net expansion (Demkowicz et al. 2011). The differing behavior is believed to be due in part to the combined effect of the neutron fluence variation across the test train (fluence was highest in the axial center) and the effect of energetic ions generated from the ${ }^{10} \mathrm{~B}(n, \alpha)^{7} \mathrm{Li}$ reaction, which occurred with higher frequency in Holders 2 through 5 due to the higher initial boron content. The net effect was an increase in the temperature control gap between the graphite holder and the capsule shell for Capsules 1 and 6 and a decrease in the gap for Capsules 2, 3, and 5. Whether this behavior played a role in silver release and migration through the graphite is not known.

The Ag-110m mass balance data (Figure 14) indicate a general agreement between the capsule fission product inventory measurements and the compact inventory measurements from Harp 2013 (i.e., the capsules with the highest measured fraction of Ag-110m on the capsule components have the lowest total retained fraction in the compacts).

\subsection{Cesium}

Cs-134 release from the compacts in Capsules 1 through 4 was less than $3 \times 10^{-6}$, well below the level of a single particle inventory $\left(2 \times 10^{-5}\right)$, indicating excellent cesium retention. Higher fractional release of cesium was found in Capsules $5\left(1.22 \times 10^{-5}\right)$ and $6\left(1.33 \times 10^{-5}\right)$, corresponding to $61 \%$ of the equivalent inventory of an average Capsule 5 particle and $66 \%$ of the equivalent inventory of an average Capsule 6 particle, respectively. Note that, similar to the Ag-110m data, the majority of Cs-134 in Capsule 6 was found on the capsule shell, while the majority in Capsule 5 was found in the graphite holder.

As discussed in Section 2.2, a region of elevated Cs-134 activity was detected in the Capsule 6 graphite fuel holder at a location corresponding to the original location of Compact 6-3-2. Upon deconsolidation-leach-burn-leach analysis of this compact (Demkowicz et al. 2012b), evidence was found for a single particle with a defective $\mathrm{SiC}$ layer. Thus, it appears that the Cs-134 found in the graphite holder originated primarily from this particle. Considering the predicted Cs-134 activity in Compact 6-3-2 (Sterbentz 2011), the inventory released from the compact corresponds to $98 \%$ of the equivalent inventory of an average Compact 6-3-2 particle.

The elevated Cs-134 activity in the Capsule 5 graphite holder was concentrated around the original location of Compacts 5-2-1 and 5-2-3 (see Section 2.2). Considering the predicted Cs-134 activity of Compacts 5-2-1 and 5-2-3 (predicted inventories were very similar in these two compacts), the inventory in the holder corresponds to $55 \%$ of the equivalent inventory of an average Compact 5-2-1 or 5-2-3 particle. Both of these compacts were sent to Oak Ridge National Laboratory to be deconsolidated and the particles gamma counted in an attempt to find any particles with an abnormally low cesium inventory, indicative of in-pile cesium loss due to a defective or failed $\mathrm{SiC}$ layer. Preliminary IMGA results from Compact 5-2-3 indicate that two particles were found to have abnormally low Cs-137 inventory but 
normal Ce-144 activity, which suggest loss of cesium during irradiation. The two particles both apparently lost approximately 30\% of their predicted Cs-137 inventory (see the August 2012 Very HighTemperature Reactor Program Monthly Report, INL/LTD-11-23807, Revision 6). Therefore, the total amount of Cs- 137 lost from these two particles (equivalent to about $60 \%$ of an average single Compact 5-2-3 particle inventory) agrees remarkably well with the finding of 55\% of an average single Compact 5-2-3 particle Cs-134 inventory found in the capsule components. Non-destructive examination of the two particles using $\mathrm{x}$-ray imaging indicates that both appear to have a crack in the $\mathrm{SiC}$ layer. Results of analysis of Compact 5-2-3 will be presented in a future topical report. Examination of Compact 5-2-1 to locate any additional particles that might have released cesium during irradiation has not yet been performed.

The results presented here demonstrate the feasibility of identifying a specific fuel compact with one or more particles that have released significant fractions of cesium in-pile, based on elevated cesium concentration in the graphite fuel holder. The compact can then be deconsolidated, specific particles with low cesium inventory located through gamma analysis, and detailed examinations of the particle(s) performed to determine the cause of cesium release.

\subsection{Europium}

Eu-154 release from the compacts was less than $1.7 \times 10^{-4}$ in four of the AGR-1 capsules. Slightly higher release was observed in Capsule $3\left(4.46 \times 10^{-4}\right)$ and Capsule $6\left(4.75 \times 10^{-4}\right)$. The measureable inventory of Eu-154 in all capsules was in excess of a single particle inventory and indicates release of europium through intact SiC. Capsules 3 and 6 both contained AGR-1 baseline fuel, but the average temperatures of the fuel compacts in the two capsules were substantially different (Hawkes 2012). The elevated Eu-154 release in these two capsules may be related to the fuel type, but a definitive explanation is not available at this time. In fuel with initial stoichiometry similar to the AGR-1 kernels (approximately $68 \%$ uranium oxide, 32\% uranium carbide [Maki 2009]), thermochemical calculations predict that europium will exist as the carbide in the burnup range under consideration (Homan et al. 1977), which is somewhat more mobile relative to the oxide at the peak irradiation temperatures in AGR-1. It should be noted that available data on several fuel compacts indicate the fraction of europium retained in the compact matrix is always higher than the fraction observed in the capsule components (Demkowicz et al. 2012a). Thus, the actual fraction of europium released from the particles is higher than the amount released from the compacts (i.e., the fractions presented in Table 7), with most of the released europium retained in the compact matrix.

\subsection{Strontium}

Total Sr-90 fractional inventory on the capsule components only exceeds a single particle inventory in Capsule 1, while in the remaining capsules the values are all below $10^{-5}$. These levels generally indicate very low release from the compacts. The Sr-90 values in all capsules are well below those of Eu-154, and there does not appear to be a strong correlation between the two data sets.

\subsection{Palladium}

The presence of 0.1 to $1 \%$ of the predicted capsule inventory of Pd-105 in the leach solutions from two of the graphite holders (Holders 1 and 2, see Section 2.2 and the appendix) suggests that palladium release from intact coatings can be significant. However, inconsistent results from the other holders and various complications with the analysis technique make comparison of results from the various graphite holders problematic. 


\section{CONCLUSIONS}

The important conclusions drawn from these results are summarized as follows:

- The radioactive fission products that were found most frequently in the capsule components were Ag-110m, Cs-134, Cs-137, Eu-154, and Sr-90.

- Ag-110m was released from the compacts in significant fractions. The fraction found in the components ranged from $1.2 \times 10^{-2}$ (Capsule 3 ) to $3.8 \times 10^{-1}$ (Capsule 6), indicating significant release of silver through intact TRISO coatings in all capsules.

- Cesium release from particles with intact $\mathrm{SiC}$ was extremely low. Fractional inventory of Cs-134 in the capsule components was less than $3 \times 10^{-6}$ in Capsules 1 through 4 , well below the inventory of a single particle. This demonstrates excellent cesium retention by the AGR-1 particles.

- The Cs-134 inventory in the components of the remaining two capsules reflected cesium released from one or more particles with defective or failed SiC. Mapping of the cesium in the graphite holders allowed specific compacts with such particles to be located in order to perform subsequent PIE to find and characterize the particles.

- Fractional inventory of Eu-154 in the capsule components ranged from 1.30 to $4.75 \times 10^{-4}$, exceeding an equivalent single particle inventory in all capsules and indicating europium release through intact coatings.

- Strontium release from the compacts was generally very low. Fractional inventory of Sr-90 on the capsule components was less than $3 \times 10^{-5}$.

- Palladium release from compacts in Capsules 1 and 2 was relatively high (Pd-105 fractional inventory of approximately $10^{-2}$ and $10^{-3}$, respectively), indicating significant release through intact coatings. It is not clear if the very low levels found in the other four capsules represent low palladium release or problems with the analysis technique.

- The data do not indicate an obvious superiority of any of the fuel types in terms of capsule-average fission product retention of the compacts. Slightly higher europium release by the baseline fuel in Capsules 3 and 6 was observed; this should be explored further during destructive fuel compact PIE. However, the very wide range of temperatures experienced by the compacts within a specific capsule makes broad comparisons of this nature among the capsules difficult.

\section{LESSONS LEARNED AND RECOMMENDATIONS}

The original expectation was that the graphite holder gamma scanning results would be only semi-quantitative primarily due to the non-ideal geometry and the need to sum the activities from numerous separate scanning steps (roughly 80 separate steps are required to cover an entire graphite holder), which could introduce errors. However, the final results of the AGR-1 graphite holder analysis indicate very good agreement between total fission product activities obtained from the gamma counting of the crushed graphite holders and summing the activities of the individual gamma scan steps. This demonstrates that gamma scanning provides good absolute activity data with proper detector calibration. Nonetheless, crushing the graphite holders for transfer to the Analytical Laboratory is still required in order to analyze for Sr-90 and any stable isotopes of interest.

The gamma scanning approach for the graphite holders proved to be very successful at achieving the experiment objectives, specifically, determining the spatial distribution of fission products with sufficient resolution to determine a particular compact of origin. The results indicate that the detection limits of the Precision Gamma Scanner were sufficiently low for cesium isotopes released from a single particle to be detected in the graphite holder, although it is clear that this is dependent to a certain extent on the fraction 
of the cesium that was retained in the graphite holder versus the fraction that migrated to the capsule shell (note that in Capsule 6 the majority of cesium was on the capsule shell and the cesium in the graphite holder was somewhat difficult to detect). This demonstrates the very important capability of identifying a specific compact that might have particles with defective $\mathrm{SiC}$ layers, which can subsequently be located for further study. It is recommended that a similar approach be used to analyze fission products in the AGR-2 graphite holders. In addition, a modified method using the same gamma scanning system may be useful to map fission products in the AGR-3/4 matrix and graphite rings.

Additional processing of the graphite holders to obtain data on non-gamma-emitting isotopes (including Sr-90 and Pd-105) proved to be much more complex than originally anticipated. It is believed that the difficulty encountered in oxidizing and leaching these components can be attributed to the addition of boron carbide to the holders prior to irradiation, which substantially enhanced the oxidation resistance of the graphite compared to graphite without boron carbide. The development of adequate methods to completely digest the holders in order to transfer the analytes of interest into solution for subsequent measurement proved to be both time consuming and expensive. While several different types of leaching and oxidation processes were used in an attempt to transfer all of the elemental constituents in the holders into solution for analysis, the final data do not indicate that any of these processes were obviously superior. If measurement of non-gamma-emitting isotopes is desired in future experiments (e.g., AGR-2), additional development may be required to obtain satisfactory results.

Results from gas exit line analysis indicated that no gamma-emitting fission products were migrating to the gas exit lines in significant quantities. In addition, embrittlement of the lines during irradiation made analysis by the originally envisioned method impractical. Because fission product inventory in the gas line segments analyzed was negligible and did not contribute significantly to the overall capsule mass balance, complete analysis of the entire length of the gas lines was abandoned. In addition, it is recommended that no analysis of gas exit lines in the AGR-2 capsules be performed in order to focus resources on more beneficial PIE activities.

\section{REFERENCES}

Chadwick, M. B., et al., 2011, "ENDF/B-VII.1 Nuclear Data for Science and Technology: CrossSections, Covariances, Fission Product Yields and Decay Data," Nuclear Data Sheets, Vol. 112, pp. 2887-2996 specific decay data accessed at: http://www.nndc.bnl.gov/exfor/endf00.jsp.

Collin, Blaise P., 2012, AGR-1 Irradiation Test Final As-Run Report, INL/EXT-10-18097, Revision 1, June 2012.

Demkowicz, P.A., 2010, “AGR-1 Post-Irradiation Examination Plan,” PLN-2828, Revision 1, March 2010

Demkowicz, P., L. Cole, S. Ploger, P. Winston, 2011, AGR-1 Irradiated Test Train Preliminary Inspection and Disassembly First Look, INL/EXT-10-20722, January 2011.

Demkowicz, P. A., J. D. Hunn, R. N. Morris, J. M. Harp, P. L. Winston, C. A. Baldwin, F. C. Montgomery, S. A. Ploger, 2012a, "Preliminary results of post-irradiation examination of the AGR-1 TRISO fuel compacts," HTR2012-3-021, Proc. HTR 2012 Tokyo, Japan.

Demkowicz, P. A., J. M. Harp, P. Winston, and S. A. Ploger, 2012b, AGR-1 Fuel Compact 6-3-2 PostIrradiation Examination Results, INL/EXT-12-27213, December 2012.

Harp, J. M., 2013, “Analysis of Individual Compact Fission Product Inventory and Burnup for the AGR-1 TRISO Experiment Using Gamma Spectrometry,” ECAR-1682, Revision 1, February 2013.

Harp, J. M. and S. A. Ploger, 2011, "Examination of Graphite Fuel Compact Holders for the AGR-1 TRISO Experiment using Gamma Spectrometry,” ECAR-1709, November 2011. 
Hartwell, J. K., D. M. Scates, J. B. Walter, M. W. Drigert, 2007, Determination of the quantity of I-135 released from the AGR-1 test fuels at the end of ATR operating cycle 138B, INL/EXT-07-12455.

Hawkes, G. L., 2012, “AGR-1 Daily As-Run Thermal Analyses,” ECAR-968, Revision 3, May 2012.

Homan, F. J., T. B. Lindemer, E. L. Long, Jr., T. N. Tiegs, and R. L. Beatty, 1977, "Stoichiometric Effects on Performance of High-Temperature Gas-Cooled Reactor Fuels from the U-C-O system," Nuclear Technology, vol. 35, 1977, 428-441

Maki, J. T., 2009, AGR-1 Irradiation Experiment Test Plan, INL/EXT-05-00593, Revision 3, October 2009.

Moreland, K., 2009, "Diverging Color Maps for Scientific Visualization," Proc. 5th Int'l Symp. Visual Computing (ISVC 09), Springer pp.92-103.

Scates, D. M., J. B. Walter, M. W. Drigert, E. L. Reber, and J. M. Harp, 2010, "Fission Product Monitoring and Release Data for the Advanced Gas Reactor 1 Experiment," Proc. HTR 2010, Prague, Czech Republic.

Simonds, J., 2010, “Technical Program Plan for the Next Generation Nuclear Plant/Advanced Gas Reactor Fuel Development and Qualification Program," PLN-3636, September 2010.

Sterbentz, J. W., 2011, "JMOCUP As-Run Daily Depletion Calculation for the AGR-1 Experiment in the ATR B-10 Position,” ECAR-958, Revision 1, August 2011. 


\section{Appendix A}

\section{Oxidation and Leach of Graphite Fuel Holders}

The proposed approach to analyze the inventory of non-gamma-emitting isotopes (including Sr-90 and Pd-105) in the graphite fuel holders was oxidation in air followed by acid leaching of the residue and analysis of the leachant solutions. This approach presumed that graphite readily oxidizes in air at elevated temperatures. However, as work progressed it became clear that heating the holder fragments in air was not sufficient to completely oxidize the graphite and produce material that could be readily dissolved. It is believed that this is primarily due to the presence of boron carbide in the graphite $\left(\mathrm{B}_{4} \mathrm{C}\right.$ was added to the AGR-1 graphite holders as a burnable poison), which can inhibit oxidation of carbon at temperatures below $1000^{\circ} \mathrm{C}$ (L. Snead and T. Burchell, "Oxidation of High-Quality Graphite for IFE," HAPL Review Meeting, November 13-14, 2001, Oak Ridge National Laboratory). Numerous modifications to the procedure were implemented with varying levels of success. Details of the process evolution are given in this appendix.

\section{Process 1: Direct oxidation-leach}

The Capsule 3 graphite holder was the first to be processed. The direct oxidation steps were performed between June and August 2011. The broken pieces of the graphite holder were placed in a 100 $\mathrm{ml}$ tall-form fused silica beaker which was, in turn, placed in a second outer silica beaker with a loosefitting cover and put into the Hot Cell 5 muffle furnace for oxidation at $500^{\circ} \mathrm{C}$. After several iterations adding up to a total of 168 hours, qualitative visual observation indicated that the dark gray graphite was volumetrically reduced by greater than $50 \%$. The second burn cycle was maintained at $750^{\circ} \mathrm{C}$ for 40 hours. The inner beaker containing the graphite cracked and separated into two sections, and the components were put into a larger silica beaker for continued oxidation. At completion of this step, the volume reduction was estimated to be $80 \%$. Because significant solids still remained, additional oxidation cycles were performed. For the next two cycles, the temperature was increased to $900^{\circ} \mathrm{C}$ and maintained for 24 and 64 hours, respectively. Following each cycle of oxidation, the sample was visually inspected to determine the degree of progress. The final residue included a combination of black material that appeared to be fused to the beaker and some white solids that flowed from the original broken beaker into the outer beaker. The residue was leached with $8 \mathrm{M}$ nitric acid in two steps, where after 25 hours the leachate was cloudy white with a white viscous residue following decanting of the liquid. The large beaker was then refilled with $8 \mathrm{M}$ nitric acid and heated for 45 minutes, and the leachate poured through a glass wool filter to collect undissolved solids. Some small black particles were visible among the white material in the filter. At this point the process was terminated and the collected leach solution amounted to approximately $280 \mathrm{~mL}$. From this volume $15 \mathrm{~mL}$ aliquots were extracted and analyzed with gamma spectrometry, ICP-MS (inductively coupled plasma mass spectrometry), and strontium-selective separation followed by gas flow proportional counting for Sr-90.

The second sample oxidized was that of Capsule 5. The process steps were performed between November 2011 and January 2012. Initial temperature was $750^{\circ} \mathrm{C}$, which was maintained for 136 hours and resulted in a nominal volume reduction of approximately $40 \%$. The furnace auxiliary blower was set at $8 \mathrm{~V}$, which produces a minimal flow, enough to cause the visual indicator pinwheel to rotate slowly. Again, the graphite was placed in an inner and outer beaker combination with the outer beaker covered. Following the burn phase the pieces in the beaker were generally white on the surface. The second burn was continued for 15 hours at $750^{\circ} \mathrm{C}$ and 24 hours at $900^{\circ} \mathrm{C}$. The sample appeared to have melted and the inner beaker containing the graphite showed some cracking. The third burn was performed at $900^{\circ} \mathrm{C}$ for 96 hours. The graphite was reduced to approximately $15 \%$ of the original volume, respectively. The slow 
rate of decomposition led to the conclusion that the material did not have sufficient oxygen supply during heating for complete oxidation. Reconfiguration of the beaker lid to allow more air flow and increasing the power to the furnace blower were tried in an effort to improve the oxidation rate. The fourth burn was performed for 55 hours at $900^{\circ} \mathrm{C}$ with the furnace fan at $80 \%$ of maximum voltage and the beaker covers removed. The residue at the end of the burn was largely unchanged from previous burn steps. Leaching was performed on the residue resulting from the numerous burn steps using $8 \mathrm{M} \mathrm{HNO}_{3}$ with 3 drops of $\mathrm{HF}$ to ensure dissolution of actinides. Three leaches were performed. In the first leach, the white material on the surface of the sample separated from the bulk material and floated to the surface, forming a nominally solid surface. The second and third leaches were performed using only $8 \mathrm{M} \mathrm{HNO}_{3}$, in which suspended visible particulate was observed. This particulate settled into a layer approximately $6 \mathrm{~mm}$ thick after 24 hours. Net leach volume was $228 \mathrm{ml}$, with aliquots taken for strontium analysis and gamma and ICP-MS performed in the MFC B-Wing hoods. The particulate was analyzed by gross gamma activity using the Hot Cell 4 spectrometer, and negligible activity above background was measured.

Given the low success with increasing access to oxygen, it was concluded that a larger surface area was needed to enhance oxidation of the carbon. The first sizing tool developed was a remote jaw crusher, which required significant force and multiple repetitions to operate, causing operator fatigue and partial failure of one of the manipulators. The improved grinder was a manual rotary tool that was able to reduce the holder pieces to approximately 5-mm diameter pieces and fines.

Compact Holder 6 was processed next. The graphite pieces were ground using the rotary tool described above. As with the two previous holders, significant volume changes were observed following the first burn cycles, but it became apparent that after the initial changes there was no further reduction in the volume of solids. Net reduction of graphite volume appeared to be no greater than $50 \%$. Multiple leaches with nitric acid generated approximately $525 \mathrm{ml}$ of solution, which was analyzed with gamma and ICP-MS, and strontium-selective separation followed by gas flow proportional counting for Sr-90

\section{Process 2: Leach-oxidation-leach}

After consideration of the various chemical components of the system, it was concluded that lithium formed from neutron activation of the boron carbide neutron poison added to the holder material in 5.5 to $7 \%$ concentrations. This had been converted into lithium carbide, which forms a water-soluble glassy material. $\mathrm{The} \mathrm{Li}_{2} \mathrm{C}_{2}$, when heated, appears to form a gas-impermeable glassy layer that impedes oxidation. When exposed to water, the $\mathrm{Li}_{2} \mathrm{C}_{2}$ readily hydrolyzes, releasing acetylene gas $\mathrm{C}_{2} \mathrm{H}_{2}$ and forming $\mathrm{LiOH}$.

A combined grinding and water leaching approach was tested on Holder 4, using frit-bottom fused silica beakers that allowed the leached graphite to be transferred directly to the furnace after draining off the leachate. Leaches were performed using demineralized water. Seven cycles of leaching and oxidation were performed before the process was interrupted by the MFC safety standown in March 2012. The multiple leaches generated approximately $3 \mathrm{~L}$ of solution, which was concentrated to approximately 500 $\mathrm{ml}$. Due to formation of white precipitate, $8 \mathrm{M}$ nitric acid was added to redissolve the solids. The final volume was approximately $1 \mathrm{~L}$ and was analyzed with gamma and ICP-MS, and strontium-selective separation followed by gas flow proportional counting for Sr-90

The leach-oxidation-leach process proved to be only partially successful, and ultimately, the mass loss of the holder due to leaching and oxidation was approximately $40 \%$. The dilute acid and water surface leach solutions were combined with the final acid leach solution was concentrated until a white precipitate formed. The solution was diluted until there were minimal amounts of undissolved solids, and aliquots were taken from the parent solution and transferred to the unshielded work areas for analysis for liquid scintillation for Sr-90, gamma ray and mass spectrometry. 


\section{Process 3: Fusion-leach-oxidation-leach}

Seeing the limited breakdown achieved by the leach-burn approach, it was suggested that it would be possible to remove the $\mathrm{B}_{4} \mathrm{C}$ by reacting it with potassium-sodium carbonate, leaching the fused material, then oxidizing the remaining carbon, leaving oxidized metals to be dissolved in nitric acid. Testing of the unirradiated material initially indicated that some trace metals from the graphite were detected in the final post burn leach, not in the carbonate flux leach. The effectiveness of the fusion is at least partially dependent on the particle size; therefore, a lab grinder was modified for remote operation to reduce the graphite that previously had been ground to approximately $2 \mathrm{~mm}$ to a fine powder (the consistency of flour).

Because the fusion process generates a large volume of liquid due to the multiple leaches, it was concluded that doing a complete fusion of the approximately $50 \mathrm{~g}$ of graphite holder would be prohibitive because of the generation of large amounts of waste. The approach selected was to grind the entire holder to powder and take three approximately 1-gram grab samples to represent the holder. It was assumed that the grinding process provides uniform mixing. Grinding to powder maximizes the possibility for the boron carbide to fuse with the carbonate mixture. The approximately 1 gram of graphite was then mixed with 6 grams of equal-molar sodium-potassium carbonate mixture and fused in a zirconium crucible at $750^{\circ} \mathrm{C}$ for 2 hours. The fused carbonate mixture was then dissolved in $8 \mathrm{M}$ nitric acid and the solids collected on a glass fiber filter using a vacuum filter funnel. The filter was placed in the furnace and the temperature raised to $650^{\circ} \mathrm{C}$ for a minimum of 6 hours, following which the temperature was raised to between 725 and $750^{\circ} \mathrm{C}$ for 2 hours. The stepwise approach was used because it was observed that the filter fused into a glassy mass if the temperature was maintained at $750^{\circ} \mathrm{C}$ or greater. The filter was then leached in $8 \mathrm{M}$ nitric acid with 3 drops of concentrated hydrofluoric acid. This leach solution along with the quartz filter was poured onto a cellulose nitrate filter. This oxidation-leach solution was analyzed by gamma spectrometry, ICP-MS, inductively coupled plasma atomic emission spectroscopy (ICP-AES), and strontium-selective separation followed by gas flow proportional counting for Sr-90. The material on the cellulose nitrate filter was dried and gamma counted to quantify any retained gamma emitting radioisotopes that were not dissolved during the process.

Holders 1 and 2 were processed between January 14 and 31, 2013, using an approach similar to that outlined in the previous paragraph. For both holders, the oxidation step was extended to 15 hours at $650^{\circ} \mathrm{C}$. The appearance of both holders' post-oxidation filters showed the presence of black material that did not dislodge from the surface when the filter was folded to fit into a leach beaker. Following the oxidation step, the filters were leached with $8 \mathrm{M}$ nitric acid. The leachate was analyzed for metals and radioisotopes. The entire process is summarized in the flow diagram in Figure A1. Unirradiated sample tests indicated greater than $90 \%$ mass conversion of the graphite for a single iteration. Reagent blanks consisting of 6 grams of the sodium-potassium carbonate underwent the same fusion-leach-burn-leach cycle for each of the last two holders so that it would be possible to identify residual metals introduced as impurities in the fusion carbonate. 


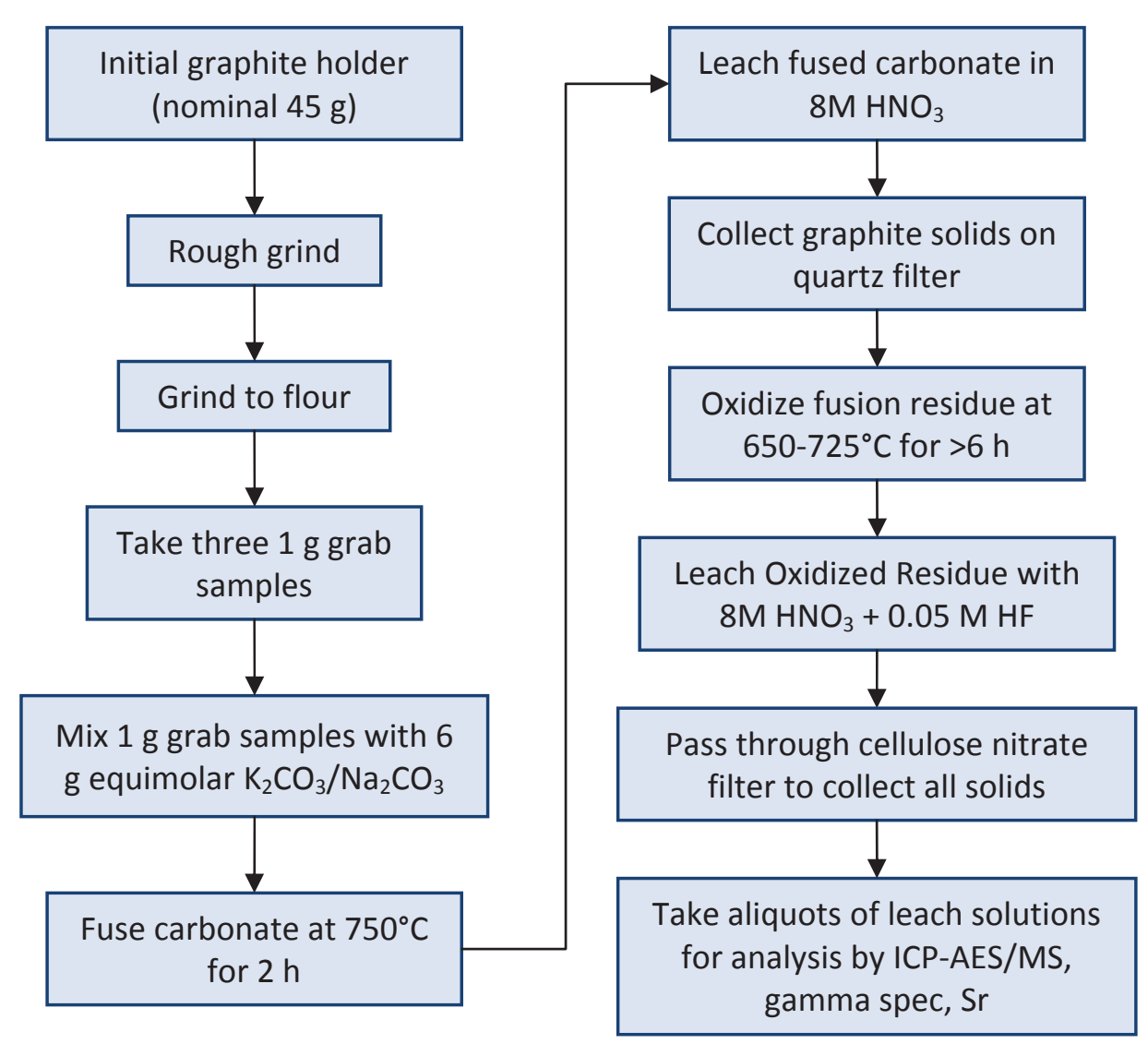

Figure A1. Flow diagram of the fusion-leach-oxidation-leach process for the AGR-1 graphite fuel holders.

To help determine the efficacy of elemental recovery from the graphite holders using the fusionleach-oxidation-leach process, several unirradiated pieces of raw material used to fabricate the AGR-1 graphite holders were processed in the same manner as Holders 1 and 2 and the solutions analyzed using ICP-MS as well as ICP-AES for elements that were present as contamination in the AGR-1 graphite (including $\mathrm{Fe}, \mathrm{V}, \mathrm{Ti}$, and $\mathrm{Al}$ ).

\section{Process evaluation using gamma emitting isotopes}

The activity of several gamma emitting isotopes measured in the solid pieces of the graphite holders (as described in Section 2.2) and in the holder leach solutions (prepared as described in this appendix) were compared as a measure of the efficiency of elemental recovery achieved in the leach processes. Table A1 gives the ratio of decay-corrected activity measured in the leach solutions to the decaycorrected activity measured in the solid graphite holder pieces prior to holder leaching. Assuming quantitative measurement of the activity in the samples, this provides an approximate measure of the recovery. In cases where at least one of the values was below the detection limit, no ratio has been included in the Table. Note that several values significantly exceed 1.0; in the case of the europium isotopes, these are likely related to the fact that measured values from the leach solutions were often very close to the detection limits and therefore the measured activities may be biased high. There is currently no satisfactory explanation for the high values for the cesium isotopes in Holder 1. 
The data in Table A1 indicate that recovery ranged from 12\% to approximately $100 \%$ and varied significantly among the different isotopes and the six graphite holders analyzed. The Ag-110m data suggest that the fusion-leach-oxidation-leach process (Holders 1 and 2) was the most effective and recovering silver, and the Co-60 data suggest that the fusion-leach-oxidation-leach process resulted in some of the best recoveries as well. However, it is worth noting that a majority of the Co- 60 and a significant percentage of the Ag-110m was measured on the cellulose nitrate filter at the end of the process for each graphite holder (i.e., it was not dissolved into solution). Thus the data do not indicate any obvious superiority of any of the leaching processes in recovering elements from the graphite holders.

Table A1. Ratio of decay-corrected gamma activity measured in the graphite holder leach solutions to the decay-corrected gamma activity measured in the solid graphite holder pieces.

\begin{tabular}{ccccccc}
\hline Capsule & Co-60 & Ag-110m & Cs-134 & Cs-137 & Eu-154 & Eu-155 \\
\hline 6 & 0.34 & 0.31 & 0.62 & 0.45 & 0.48 & 0.77 \\
5 & 0.25 & 0.12 & 0.85 & 0.75 & 0.72 & 0.86 \\
4 & 1.11 & 0.66 & & & & 1.14 \\
3 & 0.86 & 0.53 & & 0.49 & 0.94 & \\
2 & 1.04 & 0.76 & & 0.46 & 1.28 & \\
1 & 1.06 & 0.72 & 49.38 & 3.50 & 1.76 & 2.21 \\
\hline
\end{tabular}

\section{Process evaluation using ICP-AES data}

As described above, selected elements were measured in the leach solutions using ICP-AES. This was performed for the unirradiated graphite and for Holders 1, 2, and 4. This analysis focused on transition metals that were known to be present as contamination in the graphite holders prior to irradiation. The results of this analysis will be summarized here.

The level of iron and vanadium recovered from the unirradiated graphite holders was in relatively good agreement with the predicted quantities based on pre-irradiation trace element analysis of the holders. This result indicates that the fusion-leach-oxidation-leach process was reasonably effective at recovering these elements from the graphite holders. However, the values for iron in the irradiated holders were several times higher than expected and no satisfactory explanation for this result is available. The measured values for vanadium in the irradiated holders was much higher than expected due to the presence of pieces of vanadium from the AGR-1 melt wire packages.

Measurement of aluminum and titanium in both the unirradiated and irradiated graphite was complicated by unsatisfactory detection limits or excessively high background levels.

\section{Strontium results}

The decay-correct Sr-90 activity recovered from the graphite holders is given in Table A2 along with the calculated capsule fractions. Based on the data in Table A2, it is not clear if the fusion-leachoxidation-leach process was more or less effective at recovering strontium from the holders. It is worth noting that there was no measure of how much Sr-90 was left after any of the leaching process (similar to what was accomplished by gamma counting the solids at the end of the fusion-leach-oxidation-leach process to account for undissolved gamma emitting isotopes). 
Table A2. Decay-corrected activity and capsule fraction of Sr-90 measured in the graphite holder leach solutions.

\begin{tabular}{ccc}
\hline Capsule & $\begin{array}{c}\text { Sr-90 } \\
(\mathbf{B q})\end{array}$ & $\begin{array}{c}\text { Sr-90 } \\
\text { (Capsule fraction) }\end{array}$ \\
\hline 6 & $2.49 \mathrm{E}+05$ & $1.70 \mathrm{E}-06$ \\
5 & $9.73 \mathrm{E}+05$ & $5.62 \mathrm{E}-06$ \\
4 & $1.02 \mathrm{E}+04$ & $5.50 \mathrm{E}-08$ \\
3 & $1.92 \mathrm{E}+05$ & $1.01 \mathrm{E}-06$ \\
2 & $1.05 \mathrm{E}+05$ & $5.73 \mathrm{E}-07$ \\
1 & $4.41 \mathrm{E}+06$ & $2.67 \mathrm{E}-05$ \\
\hline
\end{tabular}

\section{ICP-MS data summary}

The ICP-MS analysis for leach solutions from Holders 1 and 2 included a large list of mass numbers ranging from 85 to 243 , not inclusive. The majority of isotopes were found to fall into one or more of the following categories: (1) amount was below the detection limit; (2) the specific mass number analyzed was subject to isobaric interferences which made interpretation of the exact isotopes analyzed difficult (this includes the possibility of diatomic species, such as monoxide ions, contributing to the isobars); (3) values were extremely high, which were found to be related to high background, natural contamination, and/or material dissolved into the solutions as part of the specific leach process (includes zirconium added to the solutions because of the use of a zirconium dioxide crucible during the fusion-leach process). Ultimately, the only isotopes that were found to be present in significant quantities, had significant consequences from a TRISO fuel performance standpoint, and were not impacted by the problems listed above, were Pd-105 and Ag-109.

After detailed ICP-MS analysis of the solutions from Holders 1 and 2, the solutions from Holders 3, 4, 5, and 6 were also analyzed. Based on the Holder 1 and 2 results, and to minimize the time required for the analysis, only data for Ag-109 and Pd-105 were obtained. The Ag-109 data are in all cases in reasonably good agreement with the Ag-110m data obtained from gamma counting of the solid graphite holder pieces discussed in Section 2.2. The Pd-105 data for all six graphite holders are given in Table A3. The two major observations regarding the Pd-105 data are: (1) Pd-105 capsule fractions in the holders from capsules 1 and 2 were fairly high $\left(1.1 \times 10^{-2}\right.$ and $1.5 \times 10^{-3}$ respectively), suggesting appreciable release of palladium from intact TRISO particles during the irradiation; and (2) the Pd-105 mass in the leach solutions for the holders from the other four capsules were all below the detection limit, resulting in capsule fractions less than $7.5 \times 10^{-5}$. It is not clear why the Pd-105 inventory was significant in Holders 1 and 2 but much lower in the remaining holders. It is possible that this is related to the unique processing of Holders 1 and 2 (using the fusion-leach-oxidation-leach approach); however, no other elements (including silver) have exhibited such a large disparity in behavior of Holders 1 and 2 relative to the other holders. It is also possible that the palladium was not as stable in solution as other elements and relatively quickly precipitated from solution. This would be somewhat consistent with the data, since Holders 1 and 2 were processed last and therefore their leach solutions had the least aging time. It should be noted that the level of palladium measured in Holders 1 and 2 is of a similar magnitude to palladium that has been found in the matrix of some of the AGR-1 compacts (see, for example, John D. Hunn et al., "AGR-1 Irradiated Compact 6-1-1 PIE Report: Evaluation of As-Irradiated Fuel Performance Using Leach Burn Leach, IMGA, Materialography, and X-ray Tomography”, ORNL/TM-2012/233-R0, June 2012). 
Table A3. Measured mass of Pd-105 in the AGR-1 graphite holders and corresponding capsule fraction.

\begin{tabular}{ccc}
\hline Capsule & $\begin{array}{c}\text { Pd-105 } \\
(\boldsymbol{\mu g})\end{array}$ & $\begin{array}{c}\text { Pd-105 } \\
\text { (Capsule fraction) }\end{array}$ \\
\hline 6 & $<7 . \mathrm{E}-01$ & $<8 . \mathrm{E}-05$ \\
5 & $<4 . \mathrm{E}-01$ & $<3 . \mathrm{E}-05$ \\
4 & $<6 . \mathrm{E}-01$ & $<5 . \mathrm{E}-05$ \\
3 & $<1 . \mathrm{E}+00$ & $<7 . \mathrm{E}-05$ \\
2 & $1.90 \mathrm{E}+01$ & $1.47 \mathrm{E}-03$ \\
1 & $1.14 \mathrm{E}+02$ & $1.05 \mathrm{E}-02$ \\
\hline
\end{tabular}

